NBER WORKING PAPERS SERIES

\title{
TRANSITIONAL DYNAMICS IN TWO-SECTOR MODELS OF ENDOGENOUS GROWTH
}

Casey B. Mulligan

Xavier Sala-i-Martin

Working Paper No. 3986

\section{NATIONAL BUREAU OF ECONOMIC RESEARCH 1050 Massachusetts Avenue \\ Cambridge, MA 02138 \\ February 1992}

We thank Robert Barro, Jordi Gali, Ken Kletzer, Robert Lucas, Rodi Manuelli, Danny Quah, Chris Sims, Nancy Stokey, Visca el Barça, and participants in the European Science Foundation meeting seminar in Sitges (Barcelona), and seminars at the NBER, Boston University, Brown University, University of Chicago, Federal Reserve Bank of New York, New York University, Northwestern University, and Yale University for comments on this and on an earlier version of this paper, which circulated under the name "Two capital goods models of endogenous growth: steady state, transitional dynamics, and empirical implications." This paper is part of NBER's research program in Growth. Any opinions expressed are those of the authors and not those of the National Bureau of Economic Research. 
NBER Working Paper \#3986

February 1992

\title{
TRANSITIONAL DYNAMICS IN TWO-SECTOR MODELS OF ENDOGENOUS GROWTH
}

\begin{abstract}
The steady state and transitional dynamics of two-sector models of endogenous growth are analyzed in this paper. We describe necessary conditions for endogenous growth. The conditions allow us to reduce the dynamics of the solution to a system with one state-like and two control-like variables. We analyze the determinants of the long run growth rate.
\end{abstract}

We use the Time-Elimination Method to analyze the transitional dynamics of the models. We find that there are transitions in real time if the point-in-time production possibility frontier is strictly concave, which occurs, for example, if the two production functions are different or if there are decreasing point-in-time returns in any of the sectors.

We also show that if the models have a transition in real time, the models are globally saddle path stable. We find that the wealth or consumption smoothing effect tends to dominate the substitution or real wage effect so that the transition from relatively low levels of physical capital is carried over through high work effort rather than high savings.

We develop some empirical implications. We show that the models predict conditional convergence in that, in a cross section, the growth rate is predicted to be negatively related to initial income but only after some measure of human capital is held constant. Thus, the models are consistent with existing empirical cross country evidence.

Casey B. Mulligan

Department of Economics University of Chicago

1126 E. 59th Street

Chicago, IL 60637
Xavier Sala-i-Martin

Department of Economics

Yale University

New Haven, CT 06520

and NBER 


\section{(I) INTRODUCTION.}

The transitional dynamics of two-sector models of endogenous growth are not well understood. Following the pioneering work of Lucas (1988), a lot of the recent endogenous growth literature deals with economies with two capital goods. One of the goods is usually physical capital. The other one varies across models: human capital, embodied and disembodied knowledge, public capital, quality of products, number of varieties of products, and financial capital are some examples of stock variables that are accumslated through some investment process. The analysis in all these papers is generally restricted to the steady state in that it is always assumed that all the variables in the economy grow at their long run growth rate.

If there are initial imbalances among the different sectors, however, there may be a transitional period where the relevant variables do not behave as predicted by the steady state analysis. For instance, the initial ratio of capital stocks may not be the same as the steady state one due to some recent unusual event such as a war or a large price shock: if, starting from a steady state position, a war destroys a large fraction of the physical capital stock leaving human capital relatively unaffected, the economy will somehow have to get back to the steady state proportions by having larger (smaller) than steady state growth rates for the physical (human) capital stock. It is natural to ask how, if at all, this happens. Due to its analytical difficulty, however, these transitional dynamics are always left unexplained. This paper tries to fill this gap in the literature by studying them in detail. Even though we will be calling the 
two capital stocks 'physical' and 'human', our analysis applies to any of the two-sector models mentioned above.

There are several reasons why worrying about transitions is important and interesting. First, there is the question of whether there actually are transitional dynamics and, if there are, what they look like. One could think of different plausible ways of correcting the initial sertoral imbalances. One possibility is to invest at an infinite rate in the capital stock that is relatively scarce. That is, the economy jumps to the steady state at time zero so there are no transitional dynamics. In this model agents may find it optimal to behave this way because they can invest in one good at infinite rates by disinvesting in the other good at an infinite rate while leaving the consumption path relatively smooth. An alternative plausible conjecture is that there is a transition in real time but that it entails investment in the relatively scarce sector ONLY. If this is the case, the economy will look very much like the one-capital-good neoclassical model, the transition of which we already understand. A third plausible alternative is that the transition involves positive investment rates in both sectors. Initial imbalances are then corrected by larger investment rates in the capital stock that is relatively scarce. This raises further questions like; where are the larger investment rates coming from? In a (closed economy) one-sector model the answer is larger savings. But in the class of two-sector models we consider, investment in one sector can also be increased by reducing investment in the other sector. It would therefore be interesting to know under what conditions agents rebuild their stock of physical capital by substituting away from other capital goods rather than by substituting away from consumption. A final plausible conjecture is that initial imbalances are not corrected at all because agents find it optimal 
to invest relatively more in the stock that is relatively more abundant. That is, the model could be unstable. We believe that being able to answer all these questions is important, and we shall do so in this paper.

A second important reason for studying the transitional dynamics of two-sector models of endogenous growth is to investigate their empirical implications. Despite the theoretical appeal of the concept of steady states or balanced growth paths, there is the possibility that the data sets available to empirical researchers involve economies in the transition towards some of these ideal states. In particular, the widely used Summers and Heston (1988) data set starts five years after the second world war. It can be persuasively argued that the unusual episodes of the $1940^{\circ} \mathrm{s}$ represented shocks that took most world economies away from their steady state paths. If the model we like to use to analyze long run growth involves long transitions, we should not use the available data to empirically test the model, unless we understand its predictions along the transition. Furthermore, we should not use empirical tests (such as those developed by Bernard and Durlauf (1991)) that rely on the assumption of the economy's being in the steady state.

On the other hand, testing the transitional implications of models designed to explain long run growth may be a way to tell which ones should be used both for long run forecasting or policy advice. More specifically, using the Summers and Heston (1988) data set, a variety of researcher ${ }^{1}$ find that there is conditional convergence across countries. By that is meant that countries that are relatively poor at some initial moment (which in

1 See Barro (1991), Barro and Sala-i-Martin (1991,1992), Mankiw, Romer, and Weil (1991). 
general is 1950 or 1960 ) tend to grow faster over the next 25 to 35 years but only if some other variables (such as measures of human capital accumulation or the savings rate) are held constant. People have interpreted these findings in the light of the neoclassical model and argued that the conditioning variables tend to hold constant the steady state towards which each particular economy converges. Hence, the argument goes, the data suggest that, as predicted by the neoclassical model and contrary to the one-sector endogenous growth model's implications, countries actually converge to their own steady state at decreasing growth rates.

Thus, the one-sector endogenous growth models used as alternative hypothesis by the empirical papers above seem inconsistent with this body of evidence. Yet this does not mean that endogenous growth models with more sophisticated dynamics are inconsistent too. The problem is that the transitional dynamics of such models are not well understood - another reason why their study is important. As a matter of fact, we will show ir. this paper that these models predict that the growth rate should be negatively related to initial income, but only if some variables (such as measures of human capital and/or savings rates) are held constant. Therefore, they are consistent with the existing empirical evidence.

A third important reason to study the transitional dynamics of two-sector models is that they allow us to understand their predictions for the behavior of the economy in the short run, thereby providing integrated theories of business cycles and growth. Real business cycle theory has been relatively successful in explaining short run fluctuations by using the neoclassical growth model as the basic framework. Unfortunately, however, the neoclassical growth model leaves the determinants of long run growth unexplained. Endogenous growth theory, on the other hand, is an attempt to 
characterize the determinants of the rate of long run growth. The simpler one-sector models such as the "Ak" model tend not to have transitional dynamics which makes them uninteresting theories of the business cycle. This of course means that it is important to understand the transition of more sophisticated models of endogenous growth, such as the ones we deal in this paper.

The rest of the paper is organized as follows. In section II we present a general two-sector growth model with two capital goods. The investment in one of the two capital stocks (physical capital) is a perfect substitute for consumption, while the other (human capital) is not. In section III we characterize the solution. The next section derives necessary conditions for model to generate positive steady state growth rates (ie, endogenous growth). Section V summarizes the methodology used to analyze the transitional dynamics (Mulligan (1991) discusses the time elimination method in more detail). Sections VI and VII examine the transition of the Lucas (1988) and the general two-sector models respectively. Section VIII presents some interesting empirical implications of the models. The final section concludes.

Throughout the paper we find a number of interesting results. We highlight them with italics as we move along. 
(II) A GENERAL MODEL OF HUMAN CAPITAL AND GROWTH.

(IIa) The Setup

We assume that agents maximize a utility function of the form

(1)

$$
\int_{0}^{\infty} e^{-\rho t}\left(\frac{c(t)^{1-\theta}-1}{1-\theta}\right) d t
$$

where $c(t)$ is per capita consumption at time $t, p$ is the subjective rate of time preference, which includes population growth $^{2}$, and $\theta$ is the coefficient that measures the (constant) intertemporal elasticity of substitution. The only consumption good is measured in units of final output. Final output is produced with two capital goods which we call physical and human. Physical capital is assumed to be foregone consumption. Human capital is produced in an alternative sector (which we call the education or learning sector). Households choose a consumption path, and the amount of human and physical capital they use in each sector so as to maximize (1) subject to some accumulation constraints.

(2) $\dot{k}(t)=f\left(k_{f}(t), h_{f}(t), \hat{k}(t), \hat{h}(t)\right)-\delta_{k} k(t)-c(t)$

(3) $\dot{h}(t)=e\left(k_{e}(t), h_{e}(t), \hat{h}(t), \hat{k}(t)\right)-\delta_{h} h(t)$

$k(0)>0$ and $h(0)>0$, given.

2. That is, $\rho=\rho^{*}-\mathrm{n}$, where $\mathrm{n}$ is the exogenous rate of population growth and $\rho$ is the pure rate of time preference. 
where $\dot{k}()$ and $\dot{h}()$ are the net accumulations of physical and human capital respectively, and $f()$ and $e()$ are the (flow) productions of final output ( $f$ stands for final) and human capital (e stands for education). These two production functions are assumed to exhibit constant returns to the sector specific capital stocks: $h_{f}$ and $k_{f}$ are the effective amounts of human and physical capital employed in the final output sector, and $h_{e}$ and $k_{e}$ are the corresponding variables for the education sector ${ }^{3}$. We also allow for the possibility of externalities from the average ${ }^{4}$ stocks of capital $(\hat{\mathbf{k}}$ and $\hat{h})$ in both sectors. The reason for these externalities is that we want to allow for the production function to exhibit increasing (or decreasing) returns to scale, yet we want to have a competitive solution. The modeling of increasing returns through externalities is, after Romer (1986) and Lucas (1988), common practice among endogenous growth theorists. These externalities could be positive, negative or zero and we have no presumption over their sign.

Note that the key asymmetry between the two capital goods is that the accumulation of one of them, $k(t)$, is a perfect substitute for consumption

3

Note that we are not allowing for non-reproducible inputs such as raw labor or land. The reason is that we will end up constraining our analysis to models that display endogenous growth. This restriction limits the role for such inputs. In order to simplify notation, therefore, we decided to neglect them all together.

4

One could also assume that the externalities apply to the total (not average) stock of physical or human capital. This alternative specification would generate counterfactual scale effects.

Externalities from the aggregate level of investment in one of the two capital goods could also be introduced. Chamley (1991) shows that, at least in the Lucas (1988) specification, they yield the same results as externalities from the stocks. 
(ie, consumption subtracts from $\dot{k}(t)$ and not from $\dot{h}(t))$. Hence, even though we are calling $\mathrm{k}$ physical and $\mathrm{h}$ human capital, technically speaking, the key distinction between capital goods is whether their accumulation is a perfect substitute for consumption or not. Some of the early two-sector neoclassical models such as Srinivasan (1962), Ryder (1969), Kurz (1968), or Burmeister (1980, chapter 6) assume that the production process for consumption and capital are essentially different. Their models are slightly more complicated because they involve an additional control variable and an additional relative price. Their approach amounts to the introduction of adjustment costs in the transformation of consumption into physical capital in our model. Our simpler specification, however, seems a good place for us to start 5 .

The depreciation rates $\delta_{k}$ and $\delta_{h}$ are assumed to be constant over time and may include population growth rates (because the model is expressed in per capita terms). The depreciation of physical capital has the usual interpretation. The depreciation rate of human capital has two different interpretations. First, people tend to forget the things they learn. Second, we can interpret the infinite horizon assumption as a family whose generations are altruistically linked (as in Barro (1974)). In this setup, depreciation can be thought of as imperfect transmission of human capital

5 Another key difference with the early literature is that we will restrict ourselves to parameterizations that can generate endogenous growth. As we will argue in section IV, this simplifies our problem even further.

Within the the endogenous growth literature, Rebelo (1991) uses a two-sector model similar to the one we propose here but he confines his analysis to the steady state. Jones and Manuelli (1990) show conditions for endogenous growth in models with $N$ capital goods, where all of them are produced with a single technology, which is also used to produce output. That is, $\mathrm{F}\left(\mathrm{K}_{1}, \mathrm{~K}_{2}, \ldots \mathrm{K}_{\mathrm{N}}\right)=\dot{\mathrm{K}}_{1}+\dot{\mathrm{K}}_{2}+\ldots+\dot{\mathrm{K}}_{\mathrm{N}}+\mathrm{C}$. Again, the transitional dynamics are left unexplained. 
across generations.

We assume that the two production functions are Cobb Douglas with constant returns to the private inputs

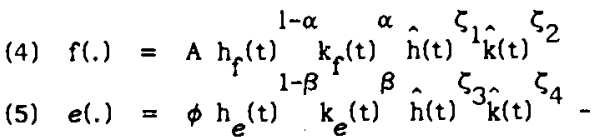

where $A$ and $\phi$ are productivity parameters that reflect the level of technology in each sector, where the physical capital shares, $\alpha$ and $\beta$, may or may not be the same in the two sectors and where the externality parameters, $\zeta_{i}$ may be positive, negative or zero.

(IIb) Point-in-Time Technologies and Point-in-Time Returns.

At every point in time, the economy-wide stocks of capital, $k(t)$ and $h(t)$ are given. Agents can generate a sector-specific capital, $k_{f}(t)$, $k_{e}(t), h_{f}(t)$, and $h_{e}(t)$, combining the aggregate stocks and effort ${ }^{6}$ with what we call point-in-time technologies ${ }^{7}$. Both humans and machines are endowed with one unit of effort, which can be allocated across the two sectors. Thus, if we define $u(t)$ as the human capital effort in the final output sector, and $\mathrm{v}(t)$ as the physical capital effort in the final output

6 We would prefer to use the word "time" rather than "effort" because we have endowments of 24 hours per day or 7 days a week in mind. However, "time" could be confused with the variable $t$ in our model.

7 This is not the first paper to consider point-in-time technologies nor is ours the first growth model that allows for decreasing point-in-time returns - see Lucas (1990) and Heckman (1976). We stress the importance of point-in-time returns for understanding transitional dynamics. 
sector, the corresponding efforts in the learning sector are $1-u(t)$ and $1-v(t)$ respectively. The point-in-time technologies for the sector specific capital stocks are

$$
\begin{aligned}
& \mathrm{h}_{\mathrm{f}}(\mathrm{t})=\mathrm{u}(\mathrm{t})^{\varepsilon_{1} /(1-\alpha)} \mathrm{h}(\mathrm{t}) \\
& \mathrm{k}_{\mathrm{f}}(\mathrm{t})=\mathrm{v}(\mathrm{t})^{\varepsilon_{2} / \alpha} \mathrm{k}(\mathrm{t}) \\
& \mathrm{h}_{\mathrm{e}}(\mathrm{t})=(1-\mathrm{u}(\mathrm{t}))^{\psi_{1} /(1-\beta)} \mathrm{h}(\mathrm{t}) \\
& \mathrm{k}_{\mathrm{e}}(\mathrm{t})=(1-\mathrm{v}(\mathrm{t}))^{\psi_{2} / \beta} \mathrm{k}(\mathrm{t})
\end{aligned}
$$

If the exponent on an effort variable is less than one, we sas that there are decreasing point-in-time returns in the production of that capital stock (see figure la). Note that in addition to exhibiting decreasing returns to effort, this specification has the property that the marginal product at zero effort is infinite. Thus, if the exponent in an effort variable is less than one, optimizing agents never choose zero effort in the production of that sector-specific stock. If the exponent in an effort variable is exactly equal to one, we say that there are constant point-in-time returns. In the case of constant point-in-time returns in all sectors, we can think of $u(t)$ and $v(t)$ as being the fraction of aggregate human and physical capital used in the final output sector at instant $t$ (and, conversely, $(1-u(t))$ and $(1-v(t))$ are the fractions used in the education sector). With the sector-specific capital production functions above, the capital accumulation equations become:

$$
\dot{k}(t)=A u(t){ }^{\varepsilon_{1}}{ }_{v(t)}^{\varepsilon_{2}}{ }_{h(t)}^{1-\alpha}{ }_{k(t)}^{\alpha} \hat{h}(t)^{\zeta} \hat{k}_{k}(t)^{\zeta}-\delta_{k} k(t)-c(t)
$$

$$
\dot{h}(t)=\phi(1-u(t))^{\psi_{1}}(1-v(t))^{\psi_{2}}{ }_{h(t)}^{1-\beta}{ }^{1-\beta(t)}{ }^{\beta} \hat{h}_{(t)}{ }^{\zeta_{3 \hat{k}(t)}}{ }^{\zeta_{4}}-\delta_{h} h(t)
$$


It is worth noticing at this point that our model includes, as a particular case, that of Lucas (1988) where the production function of human capital is assumed to use human capital only. This assumption implies that all the physical capital is employed in the output sector and, therefore, the share $\mathrm{v}$ is trivially set to one at all points in time. Furthermore, it is assumed that the production of human capital exhibits constant returns to human capital ${ }^{8}$. That is, the assumed parameters are $\zeta_{2}=\zeta_{3}=\zeta_{4}=\psi_{2}=\beta=0$, $\varepsilon_{1}=1-\alpha, \psi_{1}=1$. We also note that he imposes constant point-in-time returns. The two accumulation constraints in Lucas (1988) are, therefore

$$
\begin{aligned}
& \dot{k}(t)=A k(t){ }^{\alpha}(u(t) h(t)){ }^{(1-\alpha)} h(t)^{\zeta}-c(t)-\delta_{k} k(t) \\
& \dot{h}(t)=\phi(1-u(t)) h(t)-\delta_{h} h(t)
\end{aligned}
$$

(IIc) Convex Production Possibility Sets and Adjustment Costs.

Implicit in (2)' and (3)' is the possibility of "costs of adjustment" between the two sectors, reflected in the parameters $\varepsilon_{1}, \varepsilon_{2}, \psi_{1}$, and $\psi_{2}$. Consider the production possibilities facing a consumer at a point in time when the aggregate capital stocks are fixed. Figure $2 a$ graphs a hypothetical production possibility frontier (PPF). Given $h(t)$ and $k(t)$, agents can choose to produce a lot of education by putting zero effort in the final output sector. When $v=u=0, \phi k^{\beta} h^{1-\beta}$ units (a flow) of human capital are produced. Alternatively, agents can choose to produce a lot of final output by devoting all their effort to that sector. For $u=v=1$,

\footnotetext{
8 See Heckman (1976) for an empirical micro investigation on the relevance of such production function.
} 
$\mathrm{Ak}^{\alpha} \mathrm{h}^{1-\alpha}$ units (a flow) of physical capital are produced. Intermediate values for $u$ and $v$ will produce at points in the interior of the production possibility set (PPS).

When we say that there are adjustment costs, we mean that this production possibility set is strictly convex (production possibility frontier strictly concave). If, as in figure $2 b$, the production possibility frontier is a straight line, we say that there are no adjustment costs.

Why the term "adjustment costs?". Consider one situation where at time 1 we want to put a lot of effort and resources in the production of physical capital so that $\mathrm{u}^{\varepsilon_{1}} \varepsilon_{\mathrm{v}}$ is equal to, say, 10, and at time 2 we do not want to invest in that sector at all so $u^{\varepsilon_{1}} \varepsilon_{v}{ }^{\varepsilon}=0$. If there are adjustment costs the total flow of final and human output will be lower than in an alternative situation where $u^{1-\alpha} v^{\alpha}$ is equal to 5 in both periods. That is, as in Abel and Blanchard (1983), firms want to smooth investment over time. It is in this sense that we will think of a strictly convex production possibility set as reflecting installation or adjustment costs.

How do the parameters $\varepsilon_{1}, \varepsilon_{2}, \psi_{1}$, and $\psi_{2}$ relate to the convexity of the production possibility set at a point in time? Algebraically, it is quite complicated, but we build a lot of intuition by discussing some special examples.

EXAMPLE 1: Constant Points-in-Time Returns and Identical technologies.

Consider the case when $\varepsilon_{1}=1-\alpha, \varepsilon_{2}=\alpha, \quad \psi_{1}=1-\beta, \quad \psi_{2}=\beta$ so all the point-in-time technologies exhibit constant returns, and $\alpha=\beta$ so that the two sectors use the same production functions. That is, in the absence of 
externalities, the two capital accumulation constraints are

$$
\begin{aligned}
& \dot{k}(t)=A[v(t) k(t)]^{\alpha}[u(t) h(t)]^{1-\alpha}-\delta_{k^{k}} k(t)-c(t) \\
& \dot{h}(t)=\phi[(1-v(t)) k(t)]^{\alpha}[(1-u(t)) h(t)]^{1-\alpha^{-}}-\delta_{h} h(t)
\end{aligned}
$$

The production possibility frontier in this case is a straight line and looks like figure $2 b^{9}$.

Interesting Result \#1: If all the point-in-time technologies exhibit constant returns to scale AND the production functions in the two sectors are the same, then the point-in-time production possibility frontier is linear.

EXAMPLE 2: Constant Point-in-Time Returns and Different Technologies.

Suppose now that $\varepsilon_{1}=1-\alpha, \varepsilon_{2}=\alpha, \quad \psi_{1}=1-\beta, \quad \psi_{2}=\beta$ so all the point-in-time technologies exhibit constant returns, BUT $\alpha \neq \beta$ so that the two sectors use different technologies.

$$
\begin{aligned}
& \dot{k}(t)=A[v(t) k(t)]^{\alpha}[u(t) h(t)]^{1-\alpha}-\delta_{j k} k(t)-c(t) \\
& \dot{h}(t)=\phi[(1-v(t)) k(t)]^{\beta}[(1-u(t)) h(t)]^{1-\beta^{2}}-\delta_{h} h(t)
\end{aligned}
$$

In this case the PPF looks like Figure la so we say that there are

9 We should note that the linearity of the PPF depends on the fact that the exponents on u's and v's are the same in $f()$ and in $e() \quad\left(\varepsilon_{1}=1-\varepsilon_{2}\right.$ and $\psi_{1}=1-\psi_{2}$ and $\varepsilon_{1}=\psi_{1}$ ) rather than on the fact that the exponents on $k$ and $h$ are the same in both technologies $(\alpha=\beta)$. For instance, we can get a linear PPF with decreasing point-in-time returns in $h_{f}\left(i e, \varepsilon_{1}<1-\alpha\right)$, but only if there are offsetting increasing point-in-time returns in $k_{f}$ (ie, $\varepsilon_{2}>\alpha$ ) and the same is true for $h_{e}$ and $k_{e}$ Note also, that whether there are externalities or not has nothing to with the convexity of the PPS. 
adjustment costs. ${ }^{10}$ Note that the Lucas (1988) model falls into this category: it is a constant point-in-time returns model with a strictly convex production possibility set due to different production functions for the two sectors. Thus, the Lucas model entails adjustment costs.

Interesting Result \#2: If all the point-in-time technologies exhibit constant returns to scale BUT the production functions in the two sectors are different, then the point-in-time production possibility frontier is strictly concave.

CASE 3: Decreasing Point-in-Time Returns.

Third, suppose that $\varepsilon_{1} \leq 1-\varepsilon_{2}$ and $\psi_{1} \leq 1-\psi_{2}$, with one inequality strict. That is, suppose that there are decreasing point-in-time returns somewhere." The PPF is in this case strictly concave (as in Figure la) so we say there are adjustment costs.

Interesting Result \#3: If the point-in-time production functions in the two sectors exhibit nonincreasing returns to scale and at least one of the sectors exhibits strictly decreasing returns, then the point-in-time production frontier is strictly concave.

To summarize, non-increasing point-in-time returns are sufficient to

10

Again, we should note that the convexity of the PPS depends on the fact that the exponents on the effort variables NOT the exponents of the capital stocks are different in the two sectors (ie, what matters is that $\varepsilon_{1} \neq \psi_{1}$ and not $\alpha \neq \beta$, or whether there are externalities or not).

11 With our Cobb-Douglas production functions, decreasing point in time returns impose another condition on the PPF. If the decreasing point in time returns are in the physical capital sector, then the marginal rate of transformation must be infinite at $u=v=0$. If they are in the human capital sector then (the inverse of) the marginal rate of transformation must be zero at $u=v=1$. This extra restriction is peculiar to Cobb-Douglas. 
generate adjustment costs when the production functions are different. If the production functions are the same, then we require decreasing point in time returns somewhere.

(III) First Order Conditions, State-like, and Control-like variables.

Agents choose the paths for $c(t), u(t), v(t), k(t)$ and $h(t)$ so as to maximize utility in (1) subject to (2)' and (3)', taking $k(0), h(0), \hat{k}(t)$, and $\hat{h}(t)$ as given. The first order conditions are well known and, therefore, are confined to the appendix (see, for instance, Sala-i-Martin (1990) for a detailed derivation).

To simplify notation, we define the following parameters
(7) $\tilde{\alpha}_{1}=\alpha+\zeta_{2}$
$\tilde{\alpha}_{2}=(1-\alpha)+\zeta_{1}$,
$\tilde{\beta}_{1}=\beta+\zeta_{4}$
$\tilde{\beta}_{2}=(1-\beta)+\zeta_{3}$

The tilded variables are the elasticities for the social production function when an aggregate consistency condition is imposed. They are the sum of the corresponding private elasticity and externality parameter.

The first order condition (AB) is a relation between the fraction of physical capital, $v$, and the fraction of human capital, $u$, used in the final output,

(8) $v(u(t))=\frac{u(t)}{\Delta+u(t)(1-\Delta)} \quad$ for all $t$

where $\Delta \equiv \varepsilon_{1} \psi_{2} /\left(\varepsilon_{2} \psi_{1}\right)$ is a positive constant. Notice that equation (8) implies that when $u=1$, then $v=1$, when $u=0$, then $v=0$, and the derivative of $v$ 
with respect to $u$ is positive for all $u$ between zero and one $\left(v^{\prime}(u)=1 /\left[\Delta\{1-(1-(1 / \Delta)) u\}^{2}\right]>0\right)$. If $\varepsilon_{1} / \varepsilon_{2}=\psi_{1} / \psi_{2}, \Delta$ is equal to one all the time and therefore $v$ is always equal to $u$. That is, if the technology for producing final output is "similar" to the production for producing human capital, then the fraction of physical and human capital used in the production of final goods will be the same. The relation between the growth rate of $u$ and $v$ is $\gamma_{v}(t)=\gamma_{u}(t) /\left[1-u(t)\left(1-\Delta^{-1}\right)\right]$.

Note that (8) can be thought of as a static optimality condition. One could call $\mathrm{v}(\mathrm{u})$ the contract curve in a production Edgeworth box shown in figure 3. The dimension of the box is one by one, with the southwest and northeast corners corresponding to $(u, v)=(0,0)$ and $(1,1)$ respectively. The contract curve is the locus of points at which the isoquants for both sectors are tangent. Thus, if $v(t) \neq v(u(t))$, then output in both sectors could be increased by moving to a point on the contract curve where (8) is satisfied. In terms of the production possibility sets in figure 2 , those allocations of effort which satisfy (8) specify the frontier; the other allocations are in the interior of the production possibility set.

The monotonic relation between $u$ and $v$ indicates that economic agents never choose to increase human capital in one sector and reduce physical capital in that same sector. In other words, we can think about them deciding how much overall resources to spend in either sector and not worry too much about the exact resource (whether physical or human capital) spent since they will both move together: an extra research assistant without a computer is not good and an extra computer without a research assistant is not good either. In practice, this means that we can use either one of them as a control variable, since the other one is immediately and uniquely determined by equation (8). 
Interesting Result \#4: The optlmallty condltions require that the two effort varlables be monotonically related. We can therefore eliminate one of the control variables of the problem.

After eliminating $v(t)$, the rest of the first order conditions entail four non-linear differential equations $(\dot{u}, \dot{c}, \dot{k}, \dot{h})$ in four variables: two controls ( $c$ and $u$ ) and two states ( $k$ and $h$ ). To solve for the transition, our goal is to flnd some figures with steady state points and trajectories displaying movement towards or away from them (just like the phase diagram in the one-sector neoclassical growth model). In order to achieve this goal we face two problems. First, we are dealing with four-dimensional spaces whlch are hard to graph. Second, because we want to allow for the possibility of positive steady state growth rates, some of the four varlables may not be stationary.

In order to solve the problem of an ever growing steady state, it will be convenient to define what Mulligan (1991) calls state-like and control-llke varlables. State-like variables will be transformations of state variables only, with the property that, unlike the state variables $h$ and $k$, they remain constant and finite in the steady state. In the present model we use the following two state-like variables

(9) $z_{1}(t)=k(t) h(t)^{\tilde{\alpha}_{2} /\left(\tilde{\alpha}_{1}-1\right)}$

(10) $z_{2}(t)=k(t) h(t)^{\left(\tilde{\beta}_{2}-1\right) / \tilde{\beta}_{1}}$

Both $z_{1}$ and $z_{2}$ are increasing in $k$ and (if $\hat{\alpha}_{1}<1$ and $\hat{\beta}_{2}<1$ ) decreasing in h. One way to think about them is the following: $z_{1}^{\left(\tilde{\alpha}_{1}-1\right)}$ is the output to 
capital ratio $\bar{f}() /$.$k , when all the capital (both physical and human) is$ employed in the final output sector, that is when $u=v=1^{12}$. So in some sense, $z_{1}{ }^{\left(\tilde{\alpha}_{1}-1\right)}$ is the ratio of potential output to capital. Similarly, $z_{1}^{\tilde{\beta}_{1}}$ is the education output to human capital ratio $\overline{\mathbf{g}}(.) / \mathrm{h}$, when all the resources are employed in that sector. Hence, $z_{1}^{\tilde{\beta}_{1}}$ is the average potential output in the education sector. It is interesting to note that in the absence of externalities (so $\tilde{\alpha}_{1}=\alpha, \tilde{\alpha}_{2}=1-\alpha, \tilde{\beta}_{1}=\beta$ and $\tilde{\beta}_{2}=1-\beta$ ), both $z_{1}$ and $z_{2}$ are equal to the ratio of physical to human capital, $\mathrm{k} / \mathrm{h}$.

It will also be convenient to use control-like variables as transformations of control variables that, unlike $c(t)$, do not grow in the steady state. For most models, the ratio of consumption to physical capital will work. Thus, we just need to define a as

(11) $a(t) \equiv c(t) / k(t)$

The steady state growth rate of the other control variable $u$ (and $v$ ) is zero so we can use it as the second control-like variable.

Our next step is to rewrite the whole dynamic system using state-like and control-like variables only. To get the growth rates of the newly defined state-like variables, take logarithms and time derivatives of (9)

12 A " - " on top of $f$ and $g$ indicates potential output for that sector. That is, the instantaneous flow of output that the economy could get if all the resources were employed in that sector. 
and $(10)$ and get

(11) $\boldsymbol{\gamma}_{z_{1}}(t)=\gamma_{k}(t)-\left(\tilde{\alpha}_{2} /\left(1-\tilde{\alpha}_{1}\right)\right) \gamma_{h}(t)$

(12) $\gamma_{z_{2}}(t)=\gamma_{k}(t)-\left(\left(1-\tilde{\beta}_{2}\right) / \tilde{\beta}_{1}\right) \gamma_{h}(t)$

Rewrite the growth rate of work effort (A9) in the appendix in terms of control-like and state-like variables only

(15) $\gamma_{\mathrm{u}}=$

$e / h(1-u)\left(\left[(1-\alpha) u \psi_{1}+\varepsilon_{1}(1-\beta)(1-u)\right] / \varepsilon_{1}\right)-\theta \gamma_{c}+\left(\tilde{\alpha}_{1}-\tilde{\beta}_{1}\right) \gamma_{k}+\left(\tilde{\alpha}_{2}-\tilde{\beta}_{2}\right) \gamma_{h}-\left(\rho+\delta_{h}\right)$

denominator

where denominator $=(1-u)^{-1}\left(\left(1-\varepsilon_{1}\right)+u\left(\varepsilon_{1}-\psi_{1}\right)-\frac{(1-u) \varepsilon_{2}+u \psi_{2} / \Delta}{1-\left(1-\Delta^{-1}\right) u}\right)$ and $e$ is defined in (3). Finally, the growth rate of the new control-like variable a Is given by

(16) $\gamma_{a}(t)=\gamma_{c}(t)-\gamma_{k}(t)$

where

(17) $\gamma_{c}(t)=(1 / \theta)\left(A z_{1}(t) \tilde{\alpha}^{\tilde{\alpha}_{1}-1} u(t)^{\varepsilon_{1}-1} v(u(t))^{\varepsilon_{2}}\left(\alpha \psi_{1} u(t)+\varepsilon_{1} \beta[1-u(t))\right] / \psi_{1}-\delta_{k}-p\right)$

and where

(18) $\gamma_{k}(t)=A u(t)^{\varepsilon_{1}} v(u(t))^{\varepsilon_{2}} z_{1}(t)^{\tilde{\alpha}_{1}-1}-a(t)-\delta_{k}$ 
(19) $\gamma_{h}(t)=\phi(1-u(t))^{\psi_{1}}(1-v(u(t)))^{\psi_{2}} z_{2}(t)^{\tilde{\beta}_{1}}-\delta_{h}$

(equations (17) and (18) are found by dividing the constraints (4) and (5) by $k$ and $h$ respectively).

Interesting Result \#5: The dynamic solution to our model can be transformed into a system of four ordinary differential equations $\dot{z}_{1}(t), \dot{z}_{2}(t), \dot{u}(t)$, $\dot{a}(t))$ with two control-like variables $(\mathrm{a}(\mathrm{t})$ and $\mathrm{u}(\mathrm{t}))$ and two state-like variables $\left(\mathrm{z}_{1}(\mathrm{t})\right.$ and $\left.\mathrm{z}_{2}(\mathrm{t})\right)$ with the property that, in the steady state $\dot{z}_{1}(t)=\dot{z}_{2}(t)=\dot{u}(t)=\dot{a}(t)=0$.

Equations (12), (14), (15) and (16) plus the transversality conditions (A6) fully describe the transitional dynamics and the steady state of the model. The next section characterizes the steady state. Section (V) studies the transition.

(IV) STEADY STATE ANALYSIS.

(IVa) Necessary Conditions for Endogenous Growth.

Define steady state (or balanced growth path) as the state where all the variables grow at a constant (possibly zero) rate. Thus, we rule out paths with ever increasing growth rates, but we allow for the possibility of zero steady state growth rates.

Define "Endogenous Growth Models" as those models that can generate positive steady state growth rates of the level variables $k, h, c$, and $y$.

Equation (17) says that, in the steady state, $z_{1}$ is equal to a bunch of 
constants. Hence, $z_{1}^{*}$ is also constant and $\gamma_{z_{1}}^{*}$ (the steady state growth rate of $z_{1}$ ) is zero. Equation (18) then says that $a^{*}$ is equal to constants so $\gamma_{a}$ is equal to zero. This of course implies that the steady state growth rate of consumption is equal to that of physical capital $\gamma_{c}^{*}=\gamma_{k}^{*}$. Equation (19), on the other hand, implies that, $z_{2}^{*}$ is also equal to a bunch of constants so its value is constant and therefore, $\gamma_{z_{2}}^{*}$ is equal to zero. That is, we see that, in fact, the growth rate of the control-like and state-like variables is zero

(20) $\gamma_{z_{1}}^{*}=\gamma_{z_{2}}^{*}=\gamma_{a}^{*}=\gamma_{u}^{*}=0$

The steady state condition $\gamma_{z_{1}}^{*}=\gamma_{z_{2}}^{*}=0$ means that (12) and (14) form a homogeneous system of linear equations in $\gamma_{k}^{*}$ and $\gamma_{h}^{*}$

(21) $\left(1-\tilde{\alpha}_{1}\right) \gamma_{k}^{*}-\tilde{\alpha}_{2} \gamma_{h}^{*}=0$

$$
\tilde{\beta}_{1} \gamma_{k}^{*}-\left(1-\tilde{\beta}_{2}\right) \tilde{\gamma}_{h}=0
$$

A necessary condition for it to have positive solutions for $\gamma_{k}^{*}$ and $\gamma_{h}^{*}$ is that the determinant of the system be zero. In other words, a necessary 
condition for the model to display endogenous growth is ${ }^{13,14}$

(22) $\left(1-\tilde{\alpha}_{1}\right)\left(1-\tilde{\beta}_{2}\right)=\tilde{\alpha}_{2} \tilde{\beta}_{1}$

Note that this condition involves the elasticities of both capital goods in both social production functions (each social elasticity involves both the private elasticity and the externality parameter). In particular, it is independent of the level of technologies ( $A$ and $\phi$ ), the taste parameters ( $\rho$ and $\theta$ ), and the existence of adjustment costs (reflected in $\varepsilon_{1}, \varepsilon_{2}, \psi_{1}$, and $\psi_{2}$ ).

Interesting Result \#6: If we want the two-sector models to display positive steady state growth rates (endogenous growth) the social capital shares of the two production functions must be related according to condition 22 .

Condition (22) restricts the technologies we are allowed to use if we want the model to generate growth endogenously. To gain some intuition on what are the restrictions imposed by it, let us highlight some models that satisfy it:

(a) If there are social constant returns to physical capital in the final output sector $\left(\tilde{\alpha}_{1}=1\right)$, then we must either have the production of education independent of physical capital $\left(\tilde{\beta}_{1}=0\right)$ or the final output sector

13 The sufficient conditions and the bounded utility conditions will entail further restrictions on the size of the parameters. They will require the economy to be sufficiently productive so as to generate permanent growth but not so productive that there is no scarcity.

If we substitute using the definitions of the tilded variables, we get:

(22)'

$$
\left(1-\alpha-\zeta_{2}\right)\left(\beta-\zeta_{3}\right)=\left(1-\alpha+\zeta_{1}\right)\left(\beta+\zeta_{4}\right)
$$


independent of human capital $\left(\tilde{\alpha}_{2}=0\right)$. This latter case corresponds to the linear Ak technology used by Rebelo (1991) or Romer (1986), where output is linear in $\mathbf{k}$ and independent of human capital.

(b) If there are constant returns to human capital in the education sector $\left(\tilde{\beta}_{2}=1\right)$, then we must either have the final output sector depending on physical capital only $\left(\tilde{\alpha}_{2}=0\right)$ or the education sector depending on human capital only $\left(\tilde{\beta}_{1}=0\right)$. Notice that this latter case corresponds to the Lucas (1988) production function in equations (4)' and (5)'. We should also realize that in this case, there may be increasing, constant or decreasing returns to scale in the production of output since the conditions $\left(\tilde{\beta}_{2}=1\right)$ and $\left(\tilde{\beta}_{1}=0\right)$ impose no restrictions on $\tilde{\alpha}_{1}$ or $\tilde{\alpha}_{2}$.

(c) If both capital stocks are used in both sectors $\left(0<\tilde{\alpha}_{1}, \tilde{\beta}_{1}<1\right)$ and there are constant returns in one sector $\left(\tilde{\alpha}_{2}=1-\tilde{\alpha}_{1}\right)$, then there must be constant returns in the other sector $\left(\tilde{\beta}_{1}=1-\tilde{\beta}_{2}\right)$.

(d) If both capital stocks are used in both sectors $\left(0<\tilde{\alpha}_{1}, \tilde{\beta}_{1}<1\right)$ and there are diminishing returns in one sector $\left(\tilde{\alpha}_{2}<1-\tilde{\alpha}_{1}\right)$, then there must be exactly offsetting increasing returns in the other one $\left(\tilde{\beta}_{1}>1-\tilde{\beta}_{2}\right)$.

In terms of the Inada conditions, we know that a necessary and sufficient condition for the one capital good model to display endogenous growth is that the marginal product of capital be sufficiently bounded away from zero (Jones and Manuelli (1990)). Our analysis of the two-capital-goods models suggests that the marginal product of either capital good on either sector can approach zero as capital grows without bounds and still get endogenous growth. Condition (22) indicates, however, that the marginal product of at least one of the sectors must be bounded away from zero as physical capital tends to infinity and human capital grows 
at the corresponding optimal rate. That is, the marginal product of a "broad measure of capital" is bounded above zero.

More importantly, the necessary condition for endogenous growth (22) imposes some restrictions on the relation between $z_{1}$ and $z_{2}$. Namely,

(23) $z_{2}=z_{1} \equiv z$

This condition means that any two-sector model that is to display positive steady state growth rates can be expressed in terms of ONLY ONE state-like predetermined variable, $\mathbf{z}=\mathbf{z}_{\mathbf{1}}$.

Interesting Result \#7: The dynamic solution of any two-sector model of endogenous growth of the class consldered in this paper can be written in terms of ONE state-like variable and TWO control-like varlables.

The imposition of condition (22) is probably the main difference between the early neoclassical multi-sector neoclassical models (such as Kurz (1968), Ryder (1967), Srinivasan (1962), or Burmeister (1980, chapter 6)) and ours: it allows us to reduce our analysis by one dimension so our models are simpler.

(IVb) Steady State Comparative Statics.

The Lucas (1988) Model.

We now want to analyze the steady state behavior of some particular cases of our general two-sector model. The first one is the one proposed by Lucas (1988). As mentioned above, the main simplifying assumption is that 
the production of education exhlbits constant returns to scale to its only Input, human capltal. This simpliflcation allows for closed form solutions. The externalitles in the human capital sector are set to zero (as condition (22) requires when $\beta=0$ ). Following Lucas, however, we allow for positive externalities from the average stock of human capltal in the production of final output, $\zeta_{1}>0$. The steady state growth rates are

$$
\begin{aligned}
& \gamma_{h}^{*}=\left(\phi-\rho-\delta_{h}\right)(1-\alpha) /\left(\theta\left(1-\alpha+\zeta_{1}\right)-\zeta_{1}\right) \\
& \gamma_{c}=\gamma_{k}^{*}=\gamma_{h}\left(1-\alpha+\zeta_{1}\right) /(1-\alpha)
\end{aligned}
$$

and the steady state work effort is given by

$$
u=1-\gamma_{h} / \phi
$$

To quantify these steady state rates, let us imagine that the parameters of the model are the following: $A=1, \beta=0, \phi=1, \theta=2, \rho=065$, and $\delta_{k}=\delta_{h}=0$. The steady state growth rate Implied by these parameters is 1.757 a year. The steady state fraction of human capital devoted to the final output sector is .825 and the consumption to physical capital ratio is .1825. In Table 1 we report the signs of the derivatives of relevant steady state variables (ie, the growth rate of per capita consumption ${ }^{15}, \gamma$, the fraction of human capital employed in the final output sector, $u$, and the consumption to physical capital ratio, a ', with respect to any of the

15 The steady state growth rates of consumption and physical capital will always be the same because our formulation assumes perfect substitutability between consumption and investment. In the presence of externalities, the growth rate of human capital may be different from that of $c$ and $k$. 
parameters of the model. We observe, for instance, that an increase in the productivity parameter of the final output sector leaves the growth rate unchanged. The growth rates, on the other hand, depend positively on the level of technology of the human capital sector, and the savings parameters (negative effects of both $\theta$ and $\rho$ ). An increase in the size of either externality increases the growth rate of consumption and physical capital as the private incentives to save increase. Of course all these effects can be seen directly from the closed form formulas above.

The two-capital-goods benchmark.

The second benchmark model we want to study is one where both capital stocks are used in both sectors, and where there are no adjustment costs or externalities. The baseline parameters used are $A=1, \phi=.1, \alpha=\beta=.5, \theta=2$, $\rho=.065$, and $\delta_{k}=\delta_{h}=0$. Notice that, by equation (8), the assumption that $\alpha$ equals $\beta$ implies that $u$ and $v$ are equal at all points in time. In other words, the accumulation constraints for the second benchmark model can be written as follows:

$$
\begin{aligned}
& \dot{k}(t)=A u(t)\left(h(t)^{1-\alpha} \begin{array}{c}
k^{\alpha}(t)^{\alpha} \\
1-\alpha
\end{array}\right)_{\alpha}-c(t)
\end{aligned}
$$

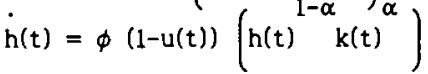

If we reinterpret $u(t)$ as the fraction of output that is left after government taxes (so $\tau(t)=1-u(t)$ is the income tax rate) and $h$ and $k$ are public and private capital respectively, this benchmark model can be interpreted as a planner's problem in a model similar to Barro (1990a) where the public input is a stock of public capital that needs to be accumulated 
rather than instantaneous public services (see Mulligan and Sala-i-Martin (1991) for a model of this type).

The steady state growth rate of consumption and capital is $\gamma=.0466$ (or 4.667. a year). In this particular parameterization with no externalities, the steady state growth rate of both capital stocks equals that of consumption. The steady state work effort or fraction of labor resources used in the production of physical goods, $u$, is .8528 and the consumption to physical capital ratio, $a^{\prime \prime}$, is .2231 .

Table 2 shows the partial derivatives of the main endogenous variables with respect to the exogenous parameters. The main difference between this and the Lucas model is that here the steady state growth rate depends positively on the productivity parameter of the final output.

\section{(V) A METHODOLOGY TO STUDY TRANSITIONS: THE TIME-ELIMINATION METHOD.}

Here we look at the two-sector growth models outside of the steady state. The basis for our analysis is the Time-Elimination Method. It provides us with a practical and efficient algorithm for solving these models numerically. Time-Elimination is discussed in detail in Mulligan (1991). Judd (1990) considers numerical techniques more generally. The Euler equations (A7) and (A9) and budget constraints (4) and (5) describe the solution for the dynamic optimization problem (1)-(5). Optimal $c(t)$, $u(t), v(t), k(t)$ and $h(t)$ are the solutions to a boundary value type system of ordinary differential equations in time. The system is (4), (5), (A7), (A9) and the boundary conditions are the Transversality Conditions (TVC) described in the appendix. Numerical solutions to boundary value problems can be found by shooting. For example, this is the methodology employed by 
King and Rebelo (1989) and Jorgenson and Jun (1990) to examine one-sector growth models.

Numerically, boundary value problems are much more difficult - both conceptually and computationally - to solve than are initial value problems ${ }^{16}$. In fact, the shooting method becomes unwieldy for more than a few dimensions. One key advantage of the Time-Elimination method is that it transforms the boundary value type problem described by (4), (5), (A7), (A9) and the TVC's into an initial value problem.

The Time-Elimination method is a four step algorithm. First, as in section II, we define the state-like variables, $z_{1}(t)$ and $z_{2}(t)$, and control-like variables, $a(t), u(t)$, and $v(t)$. As we showed in section III, the original Euler equations can be expressed in terms of $z_{1}(t), z_{2}(t)$, $a(t), u(t)$ and $v(t)$ only. But as we showed in section IV, the condition for balanced growth (condition 22) requires $z_{2}$ to be equal to $z_{1} \equiv z$. The three relevant dynamic equations (12), (15) and (17) can be written as

$$
\begin{aligned}
& \dot{z}(t)=\kappa_{1}(a(t), u(t), z(t)) \\
& \dot{u}(t)=\kappa_{2}(a(t), u(t), z(t)) \\
& \dot{a}(t)=\kappa_{3}(a(t), u(t), z(t))
\end{aligned}
$$

where $\kappa_{1}$ are complicated nonlinear functions.

Second, we argue that for (interesting) optimal solutions state-like

16 On a more pragmatic level, computer math packages are much more likely to include routines that solve initial value problems than to include routines that solve boundary value problems. We use MATLAB's ODE23 routine to solve initial value problems. We can therefore worry about economics rather than numerical mathematics (we believe that we have a comparative advantage in the former). See Press, et al (1990) for a comparison of initial value and boundary value problems. 
and control-like variables will be constant and finite in the steady state. This was shown in the last section.

Third, since the Euler equations describing the state-like and control-like variables only depend on these variables, we think about pollcy functions for the control-like variables:

$$
\begin{aligned}
& a(t)=a(z(t)) \\
& u(t)=u(z(t))
\end{aligned}
$$

Using (25), the transformed Euler equations in $z, a$ and $u$ can be manipulated to eliminate the time component as follows:

$$
\begin{aligned}
& a^{\prime}(z)=\dot{a}(t) / \dot{z}(t)=\kappa_{3}(a(z), u(z), z) / \kappa_{1}(a(z), u(z), z)=\xi_{1}(z) \\
& u^{\prime}(z)=\dot{u}(t) / \dot{z}(t)=\kappa_{2}(a(z), u(z), z) / \kappa_{1}(a(z), u(z), z)=\xi_{2}(z)
\end{aligned}
$$

The equations in (26) yield the slope of the policy functions or stable arms for all values of $z$ (except $z^{*}$ ). From step two we know the value of the policy function at the steady state (that is, the transversality conditions Imply that the policy function must go through the steady state):

$$
\begin{aligned}
& a^{*}=a\left(z^{*}\right) \\
& u^{*}=u\left(z^{*}\right)
\end{aligned}
$$

With one modification, (26) - (27) is an initial value problem. The required modification is to specify the slope of the policy function at the steady state (notice that at the steady state $\dot{a}=\dot{u}=\dot{z}=0$ so equations (26) cannot be applied directly. If one can easily distinguish stable from 
unstable arms, these slopes can be found by applying L'Hopital's rule to (26). ${ }^{17}$ Alternatively, one can linearize (26) around the steady state. The eigenvectors are tangent to the true (nonlinear) arms at the steady state and the eigenvalues can be used to distinguish stable from unstable arms. Because we did not know a priori whether the models are saddle path stable and we did not know the slope of the stable arms at the steady state, we used this second procedure.

The fourth step consists of using MATLAB's subroutine ODE23 to solve the two differential equations in (26), subject to the initial values in (27), and the steady state slopes just described. That is,

$$
\begin{aligned}
& a(z)=\int a^{\prime}(z) d z+c_{1} \\
& u(z)=\int u^{\prime}(z) d z+c_{2}
\end{aligned}
$$

where $C_{1}$ and $C_{2}$ are integrating constants. As mentioned above, these constants are determined by the fact that the policy function must go through the steady state point.

Additionally, we may be interested in finding the time path for $z$. This can be done by substituting the policy functions into (10) and (numerically) integrate with respect to $t .^{18}$ Most interesting economic questions, however, can be answered from knowledge of the policy function alone.

17 It is important to distinguish stable from unstable arms since all of them satisf $y(26)-(27)$.

18 The integration of (10) subject to some $z(0)$ is another initial value problem. 
Two of the beauties of the method used in this paper are the speed at which the computer vomits the answers and the simplicity of the programs needed: on an IBM $16 \mathrm{MHz} 386 \mathrm{SX}$, we usually can find policy functions for the problem (1) to (5) in less than 30 seconds!. We do not have the patlence to try shooting, but guess that shooting would take somewhere on the order of one hour to solve the same models.

As we argued above, the dynamics of the system are fully determined by one state-like variable, $z$, and two control-like variables, $u$ and a. The evolution of the economy can be described by a phase diagram. The stable arm (the models do turn out to be saddle-path stable) will be a one dimensional curve in a three dimensional space. This curve goes through the steady state. In order to simplify the figures, we will report the projections of this curve onto the $[u, z]$ two dimensional space and the $[a, z]$ two dimensional space separately (i.e., the policy functions $u(z)$ and $a(z)$ ).

\section{(VI) TRANSITIONAL DYNAMICS IN THE LUCAS MODEL.}

(VIa) Stability

We start by applying the methodology just described to study the transition of the Lucas (1988) model. From (9) and (10), the only state-like variable $z$ is equal to the ratio of the two capital stocks, $\mathrm{k} / \mathrm{h}$. As part of the time-elimination method just described, we need to compute the eigenvalues of the linearization of the system around the steady state. We always find that there is one negative and two positive eigenvalues so that the model is locally saddle path stable. This is true even when we include positive externalities in the final output sector so that it 
exhibits social increasing returns ${ }^{19}$.

We then apply the time-elimination method and we are able to calculate the policy functions for any value of $\mathrm{k} / \mathrm{h}$ between zero and any (arbitrarily large) positive number. This means that the model is globally saddle path stable $^{20}$.

Interesting result \#8: The Lucas (1988) model of endogenous growth is globally saddle path stable.

(VIb) Transition.

But interesting as they are, the stability properties of the model are not our ultimate goal. We want to find out what are the economic forces that lead the economy from any arbitrary initial ratio $(k / h)_{0}$ to the steady state ratio $(k / h)$.

Consider an initial condition where physical capital is relatively scarce $-(k / h)_{0}$ low. Obvlously, if the economy has to go to the steady state, economic agents must invest in physical capital more intensively. In this model there are two ways of doing that: first, they can reduce consumption (because consumption is a substitute for physical capital investment). Second, they can work harder in the final output sector (physical capital is produced out of final output). Since agents like to

19 When there are externalities, the state like variable, $z(t)$ is no longer the ratio $k / h$ (see equation (9)).

20 We never find a vertical asymptote in the policy functions either. Note that, since the policy functions are unit-valued, this implies that the steady state is unique. The policy functions are unit-valued because the Hamiltonian is concave in the choice variables.

Through independent research and drastically different methodologies, Faig (1991) and Caballé and Santos (1991) have arrived at the same conclusion. 
smooth consumption, they don't like the first choice. This is a wealth or consumption smoothing effect. Low $\mathrm{k} / \mathrm{h}$, on the other hand, implies low wages $^{21}$ and low willingness to work (low $\mathrm{k} / \mathrm{h}$ times are times to go to school). This is a substitution or wage rate effect. If agents really want to smooth (large $\theta$ ) or if the wage rate for low $\mathrm{k} / \mathrm{h}$ is not very low (small $\alpha$, the wealth effect dominates and physical capital is rebuilt with larger work effort. The policy function $u(z)$ is downward sloping. Low $\mathrm{k} / \mathrm{h}$ are therefore be associated with high consumption ratios $-\mathrm{c} / \mathrm{k}=\mathrm{a}-$ so the policy function $a(z)$ is also downward sloping. The opposite is true if the willingness to substitute intertemporally is large.

Figure 5 confirms these results. The key determinant of the slope of the policy functions is the size of $\theta$ the coefficient of intertemporal substitution - relative to $\alpha$ - the physical capital share in the output sector, which reflects how low the real wage rate is for low levels of $\mathrm{k} / \mathrm{h}$. There are three possibilities depicted in Figures $5 \mathrm{a}, \mathrm{b}$ and $\mathrm{c}$.

Figure $5 a$ shows the case when $\theta>\alpha$. As we just argued, the two policy functions are downward sloping. Note also that if $\mathrm{k} / \mathrm{h}$ is sufficiently low (far away from the steady state), $u$ is larger than one. This means that there may be disinvestment of human capital ( $u>1)$. The stable arm for $c / k$ is downward sloping; this reflects the agent's willingness to smooth consumption and the anticipation of increasing capital.

Figure 5b considers the case $\theta<\alpha$ : low willingness to smooth consumption and/or very low wages for low $\mathrm{k} / \mathrm{h}$. The two policy functions in this case are upward sloping, which means that physical capital is restored

21 The wage differential cannot be reduced by reallocating capital between the sectors because, for the Lucas model, physical capital is not used in the $h$ sector. 
through savings rather than through hard work in the final output sector as the substitution effect dominates the wealth or consumption smoothing effect. When $\theta=\alpha$, the two effects cancel out so both stable arms are flat. This is reflected in Figure 5c.

Interesting Result \#9: In the Lucas (1988) model, the transition from LOW $k / h$ ratios involves high or low work effort and consumption depending on the relative size of $\theta$ and $\alpha$. If $\theta>\alpha$, the wealth effect dominates and physical capital is restored through high work effort (and the two policy functions are downward sloping in $k / h)$. If $\theta<\alpha$, the substitution effect dominates so physical capital is restored through low consumption (and the two policy functions are upward sloping). If $\theta=\alpha$, the two effects offset (and the two policy functions are flat). The symmetric result applies for transitions from $H I G H \mathrm{k} / \mathrm{h}$ ratios.

Since, empirically we tend to think that $\theta>1$ (and therefore $\theta>\alpha$ ), we believe that the case of downward sloping policy functions is the most (only?) empirically relevant.

(VII) TRANSITIONAL DYNAMICS IN THE GENERAL MODEL: THE ROLE OF ADJUSTMENT COSTS.

(VIIa) Same Production Function in Both Sectors.

The Lucas (1988) model is a particular case where the education sector does not use physical capital as an input of production. We now want to analyze the transition of the more general model. We start with the benchmark model \#2, where the two production functions are the same, where there are constant point-in-time returns in all sectors, and where there are no externalities. From the analysis above, these assumptions imply that the two effort variables are equal at all points in time $-u(t)=v(t)$ for all 
t- The absence of externalities implies that the only state-like variable is the ratio of the two capital stocks, $z=k / h$.

The main finding here is that the policy functions $u(k / h)$ and $a(k / h)$ are vertical lines at the steady state ratio $(\mathrm{k} / \mathrm{h})^{*}$ (See figure 6). Thus, if the initial ratio is smaller than the steady state one, agents choose to invest (disinvest) at an infinite rate in the physical (human) capital sector by setting $u=\infty$. The economy immediately jumps to the steady state capital ratio. Conversely, if the initial ratio of capital stocks is above the steady state ratio, agents want to invest (disinvest) in the human (physical) capital sector at an infinite rate by setting $u=-\infty$. The ratio jumps to the steady state level immediately. The transition, therefore, take no real time.

The result of Instantaneous transition (or no transitional dynamics) applies to any model that yields a linear production possibility frontier regardless of $\alpha$ and $\beta$. Remember from section II that parameterizations that satisfy $\varepsilon_{1}=\psi_{1}=1-\varepsilon_{2}=1-\psi_{2}$ yield linear PPF's;

Interesting Result \#10: If the point-in-time production possibility frontler of a two-sector model is linear, the model entails no transition (le, the economy 'jumps' to the steady state at time zero). Thus, in order to get transitions in real time, we must have strictly convex production possibllity sets ${ }^{22}$.

22 We offer two explanations for this result. First, as an analytic matter, the Hamiltonian is linear in $u$ (after we allow for the dependence of $v$ on $u$ as specified in equation 8 ) when the PPF is linear. The maximum principle tells us that solutions are of the bang-bang control type when the Hamilitonian is linear in the control.

Second, we put forward an economic argument. The costate variables for this problem ( $\lambda$ and $\nu$ in the appendix) can be thought of as prices. Their ratio is the relative price of final output and education output. A firm chooses that relative price in the PPS that maximizes profits. For a linear PPF, no maximum exists unless there are limits on $u$ and $v$. 
(VIIb) Models with Strictly Convex Production Possibility Sets.

Our finding of optimal infinite investment rates resembles the Jorgenson (1963) one capital good neoclassical model of investment where lower than steady state capital stocks are also eliminated by infinite rates of investment. The q-theory of investment shows that the existence of adjustment or installation costs eliminates these jumps in the capital stock by introducing some incentive to smooth investment over time. Hence, we introduce adjustment costs (strictly convex production possibility sets) in the benchmark model just outlined to see whether we can get some sensible transitional dynamics ${ }^{23}$.

We know from the Interesting Results 2 and 3 that there are different ways to get strictly convex PPS's. We study these different possibilities separately. One common thing about them, however, is that the linearization around the steady state always gives one negative and two positive real eigenvalues. Hence, all the models are locally saddle path stable. This is true, even when we allow for social increasing returns to scale in one sector (and, in order to satisfy condition (22), offsetting decreasing returns to scale in the other sector). Since we are able to calculate the policy functions $u(z)$ and $a(z)$ for any value of $z$ between zero and any arbitrarily large positive number, the models are globally saddle path

23 In the neoclassical growth models, jumps in the capital stock are eliminated by the assumption that agents have concave preferences and, therefore, like to smooth consumption. In the two capital goods models considered in this paper, jumps in the physical capital stock that are accompanied by jumps in the stock of human capital are consistent with consumption smoothing. 
stable.

Interesting Result \#11: All two-sector growth models of endogenous growth with strictly convex point-in-time production possibility sets (concave PPF) are globally saddle path stable. This is true even when there are increasing returns to scale in one of the sectors ${ }^{24}$.

(VIIc) Adjustment Costs From Different Production Functions.

One way to get a strictly convex PPS is for the two sectors to have different production functions. Consider the case where there are constant point-in-time returns everywhere BUT the two production functions are different. We know from Interesting Result \#2 that the production possibility frontier is strictly concave and the marginal rate of transformation is positive and finite everywhere.

The two policy functions for the case $\alpha=.6$ and $\beta=.4$ are depicted in figure 7. As expected, we find that they both have finite slopes. Contrary to the Lucas (1988) example, we can no longer find upward sloping policy functions (not even for $\theta$ arbitrarily close to zero). We believe that the reason is that the substitution or real wage effect is no longer important: In the Lucas model, all the physical capital needs to be used in the final output sector. In the general model, on the other hand, agents can choose how much physical capital to have in each sector. Hence, to a certain degree agents can choose the wage rate by shifting capital from the education to the final output sector. Hence, the real wage rate effect is

24 Again, this result comes from extensive experimentation with all kinds of parameters and is not based on a formal proof. Strictly speaking, Interesting Result \#ll should say "We have been unable to find a model with strictly convex PPS which does not display saddle path stability and vice versa. This includes models with social increasing returns to scale in one of the sectors." 
unimportant and the wealth effect dominates. Both policy functions are, therefore, downward sloping.

Finally, for $z$ 's sufficiently below the steady state, the optimal value of $u$ is above one: it is optimal for agents to actually disinvest some human capital and install it as physical capital. For $z$ 's sufficiently large, on the other hand, the optimal value of $u$ is below zero, which indicates a willingness to uninstall physical capital and install it as human capital.

(VIId) Adjustment Costs via Decreasing Point-in-Time Returns.

Another way to generate a strictly convex PPS is to introduce decreasing point-in-time returns in any of the sectors (see Interesting Result \#3). In Figure $8(a)$ we display the policy functions associated with decreasing point-in-time returns in the physical capital sector only.

We see that both stable arms are downward sloping. As in the previous section, (and again contrary to the Lucas model) we have been unable to find parameters that generate upward sloping policy functions, not even for very small values of $\theta$. The main difference from the previous section is that $u(z)$ never takes values below zero (it asymptotes to zero as the physical to human capital ratio approaches infinity). The reason is that, in the Cobb Douglas-framework, decreasing point-in-time returns in the final output sector implies infinite marginal rates of transformation at $u=v=0$. Thus, optimizing agents never choose $u=0$.

The introduction of decreasing point-in-time returns in the education sector only yields similar results (see figure $8 \mathrm{~b}$ ). The only difference is that $u$ does not go above one but goes below zero. The reason is that we are 
assuming that the instantaneous marginal product of work effort when all the effort is employed in the human capital sector $(u=l)$ is infinite. Hence, agents never choose u's above one.

Of course, when we introduce decreasing point-in-time returns in both sectors (figure 8c) we find that the stable arms are downward sloping and the $u$ is bounded between zero and one. Note that this is true, no matter how small the departure from constant returns is. In other words, strictly decreasing but very close to constant point-in-time returns entail a $u(z)$ policy function close to horizontal at $\mathrm{u}=1$ for $\mathrm{z}$ below the steady state, close to horizontal at $u=0$ for $z$ above the steady state, and close to vertical for $z$ close to the steady state. The reason for such a big difference for small departures from constant returns (recall that constant returns entail a vertical policy function $u(z)$ ) is that the marginal product of $\mathrm{u}$ is some finite number if the point in time technology is $h_{f}=u h$, but it is infinite if $h_{\mathrm{f}}=u^{\xi}$ for $\xi$ strictly smaller than one (no matter how close to one). In other words, the PPF for constant point-in-time returns is linear at all points (including $u=l$ and $u=0$ ). An arbitrary small departure from constant returns implies a PPF close to linear everywhere but with an infinite slope at $u=1$ and a zero slope at $u=0$.

Finally, in the right hand side panels of figures $8 a, b$ and $c$ we see that the shape of the other policy function $a(z)$ is independent of these adjustment costs.

Interesting Result \#12: models with strictly convex production possibility sets (whether they are achieved through different production functions or through decreasing point-in-time returns) entall transitions in real time.

Along the transition, the wealth effect always dominates the substitution effect so the transition from $L O W \mathrm{k} / \mathrm{h}$ ratios involves high work effort and high consumption-capital ratios. Thus, unlike the particular case of Lucas (1988), the pollcy functions $a(z)$ and $u(z)$ are always downward sloping. 
If, in addition, the marginal products of effort in both sectors are infinite when effort is zero, the policy function for work effort $u(z)$ is bounded between zero and one. In the Cobb Douglas framework, decreasing point-in-time returns imply infinite marginal products of effort at zero effort.

(VIIe) Irreversible Investment.

One could plausibly argue that the effort variables should be bounded between zero and one. As we just showed, one way to get this result is to impose infinite marginal products of effort at zero effort in both sectors. Alternatively we can impose a technological constraint to $u$, say $u \in[0,1]$. This technological constraint would apply when investment is irreversible. When the constraint is binding at $u=1$, human capital grows at rate $-\delta_{h}$ and production looks like $A^{\prime} k(t)^{\alpha-1}$, until $k / h$ reaches its steady state value. This looks a lot like a one-sector growth model with exogenous labor augmenting technological change at rate $-\delta_{h^{*}}$. The equations of motion are the same, although the boundary conditions are different. An important difference is that, here, the steady state is reached in finite time after which the level of work and the consumption to capital ratio are the ones depicted in Table 1. Because one-sector dynamics have already been analyzed elsewhere and in order to limit the scope of our paper, we do not examine such one-sector dynamics resulting from constraints on $u$.

\section{(VIII) AN ANALYTICAL ANALYSIS OF THE TRANSITION}

The policy functions we have found in the previous sections can be used to derive some empirical implications of the models. Following Mulligan (1991), we arrive at a formula for consumption by making two observations. First, numerical analysis of consumption policies reveals that, for many 
growth models (including those in this paper), the consumption to capital ratio is very nearly a linear function of the average product of physical capital: $^{25}$

(30) $a(y / k) \approx \tilde{a}(y / k)=D+E \cdot(y / k)$

This of course implies that consumption is very nearly a linear function of capital and income:

$$
\text { (30b) } c(k, y) \simeq \tilde{c}(k, y) \equiv D \cdot k+E \cdot y
$$

Second, we do not see a secular trend in savings rates. One way to explain this second observation is to argue that the economy is always in the steady state. Another possibie explanation is that the parameters of the model are such that agents optimally choose constant savings rates along the transition. $^{26}$ For our two-sector models, it seems desirable, at least for special cases, that $D=0$ and $E=1-s$. Before specifying $D$ and $E$, we therefore look for special cases of human capital endogenous growth models that predict savings to be constant during the transition to the steady state. Actual policy functions satisfy the system of differential equations (25) and (26), If actual policies are to exhibit constant savings rates (at

25 Actual policies are denoted without a $\sim$. The approximations are denoted with a $\sim$. Mulligan (1991) discusses consumption policies for three growth models: Ramsey(1928)-Cass(1965)-Koopmans(1965), Jones and Manuelli (1990) and Lucas (1988).

26 Kurz (1968) shows for the one-sector neoclassical growth model that if the production function is Cobb Douglas and the utility function is CIES, then there is value of $\theta$ (the coefficient of elasticity of substitution) that makes optimal savings constant along the transition. 
rate s), it must be true that:

$$
c(k, y)=\tilde{c}(k, y)=(1-s) \cdot y
$$

equivalently,

$$
a(y / k)=\tilde{a}(y / k)=(1-s) \cdot(y / k)
$$

In terms of $z$, we want $a(z)=\left(A u^{\varepsilon_{1}} \varepsilon_{v}{ }^{\varepsilon_{z}-1}\right)$. Substitution of this particular form into the system (25) and (26) reveals that â() does not satisfy the system for all sets of parameters. For the Lucas model the savings rate is constant if:

(32a)

$$
\theta=\frac{\left(\rho+\delta_{k}\right) \alpha}{\alpha \delta_{k}-(1-\alpha)\left(\phi+\delta_{k}\right)}
$$

and the constant savings rate is

$$
\mathbf{s}=1-(\theta-1) \alpha / \theta
$$

Assuming $\theta, \phi, \alpha$, and $\delta_{k}$ are all nonnegative, it is clear from (32) that $\alpha$ must necessarily be greater than .5 and $\delta_{k}$ must necessarily be positive if savings rates are to be constant in the transition and utility is to be concave.

Interesting Result \#14: There is a set of parameters that yield constant savings rates along the transition of the Lucas model. The parameters must satisfy condition (34).

A constant savings rate benchmark suggests some choices for $D$ and $E$ : 
(33)

$$
D=\left(\phi+\delta_{k}\right)(1-\alpha) / \alpha+\left(\rho+\delta_{k}\right) / \theta-\delta_{k}
$$

$E=(\theta-1) \alpha / \theta$

The linear approximation $\tilde{a}(y / k)$ - wlth $D$ and $E$ chosen as in (33) exhibits four desirable properties that suggest that it is a good approximation to the true policy function $a(y / k)$ :

(i) $\tilde{a}(y / k)$ is exactly correct when savings rates are constant

ie, $\tilde{a}(y / k)=a(y / k) \quad$ when $\theta=\frac{\left(\rho+\delta_{k}\right) \alpha}{\alpha \delta_{k}-(1-\alpha)\left(\phi+\delta_{k}\right)}$

(ii) $\tilde{a}(y / k)$ passes through the steady state

$a^{*}=a\left((y / k)^{*}\right)=\tilde{a}\left((y / k)^{\prime \prime}\right)$

Even when the savings rate is not constant, $\tilde{a}(y / k)$ should be a very good approximation near the steady state.

(iii) $\tilde{a}(y / k)$ is linear in $(y / k)$

This is a nice property because numerical analysis has shown $a(y / k)$ to be very nearly linear in $(y / k)$

(iv) $\tilde{a}(y / k)$ is increasing in $(y / k)$ for $\theta>1$

For the Lucas model, $a(y / k)$ is increasing for $\theta>\alpha$

Interesting Result \#15: Consumption is very nearly a linear function of capital and income so $\mathrm{c}(\mathrm{k}, \mathrm{y})=\mathrm{D} \cdot \mathrm{k}+\mathrm{E} \cdot \mathrm{y}$, where $\mathrm{D}$ and $\mathrm{E}$ are the following constants:
$D \equiv\left(\phi+\delta_{k}\right)(1-\alpha) / \alpha+\left(\rho+\delta_{k}\right) / \theta-\delta_{k}$
$E=(\theta-1) \alpha / \theta$ 
(VIIIb) Conditional Convergence.

Some of the empirical growth literature has reported cross section growth regressions where growth is shown to depend negatively on initial income after some measures of human capital and/or savings rates are held constant. The one-sector neoclassical model is consistent with this empirical evidence while the one-sector linear-technology endogenous growth model is not. In this section we want to ask what is the prediction of the transition of the two-sector endogenous growth models studied in this paper.

We first derive a closed form growth expression that depends on two assumptions: that $a(y / k)$ is very nearly linear in $(y / k)$ and that its slope is less than $\alpha$. Either an examination of the $\tilde{a}(y / k)$ suggested in the previous section or numerical analysis supports these assumptions. ${ }^{27}$ Using the production function $y=u^{1-\alpha_{k} \alpha_{h} 1-\alpha}$, the Euler equations, budget constraints and a linear approximation to $a(y / k)$, one finds that output growth is a linear function of $(y / k) .^{28}$

$$
\gamma_{y}=G_{1}+G_{2}(y / k)
$$

27 The slope of $a(y / k)$ is not always less than $\alpha$ when $\alpha$ is small and $y / k$ is small (in such cases constant savings is not possible). Since the convergence implications which follow depend on this assumption about the slope of $a(y / k)$, they are questionable for small $\alpha$ and small $y / k$.

28 For some definitions of $h$, it may be the case that activities in the $h$ sector are included in measured GDP. Rather than considering final output, $y$, one may want to think about "full output", $Y$, which could be defined as the sum of outputs in both sectors, weighted by relative prices:

$\mathrm{Y} \equiv \mathrm{y}+\frac{\lambda}{v} \cdot(\delta \cdot(1-\mathrm{u}) \cdot \mathrm{h})$

where $\lambda$ and $v$ are the shadow prices defined in the appendix. For this alternative definition of output, one obtains a similar growth expression: 
where $G_{1} \equiv\left(\phi+\delta_{k}\right)(1-\alpha) / \alpha-\delta_{k}-D$ and $G_{2} \equiv \alpha-E$ are constants. Note that output growth is increasing in $(y / k)$ for $E<\alpha$. This is certainly true when $D$ and $E$ are chosen so as to yield constant savings rates (condition (33)). As an example, for constant savings rates parameterizations, output growth in (34) is:

$$
\gamma_{y}=\left(\alpha y / k-\left(\rho+\delta_{k}\right)\right) / \theta
$$

Naturally, if savings rates are constant, the growth rate of output is the same as the growth rate of consumption. Since many empirical studies do not have data for $(y / k)$, a substitution for $(y / k)$ (derived from the production function alone) yields an expression that may be more useful for empirical analysis.

$$
\gamma_{y}=G_{1}+G_{2} \cdot\left(\frac{u \cdot h}{y}\right)^{\frac{1-\alpha}{\alpha}}
$$

That is, output growth is an increasing function of human capital augmented by labor supply and a decreasing function of initial output. For a broad sample of countries, Barro (1991) finds that the simple correlation between output growth and initial income is zero. Once he holds constant some measure of human capital, however, he finds that the partial correlation

$$
\gamma_{Y}=G_{1}(u)+G_{2}(u) \cdot(y / k)
$$

Here, $G_{1}$ and $G_{2}$ are not constant but are functions of $u$. $G_{2}$ is still positive, which means that all of the qualitative results that were obtained for $y$ still hold for $Y$. 
between growth and initial output is negative. This is consistent with the Lucas model since, if the initial stock of human capital is correlated with initial income, its omission from the regression tends to bias the coefficient on income towards zero ${ }^{29}$. Borrowing terminology from Barro (1991), the Lucas model predicts "Conditional Convergence" in that the simple correlation of growth with initial income will be zero but it will turn negative after holding constant human-capital-augmented work effort. If the latter variable is not very correlated with income within the sample of countries, then the simple correlation will be negative. This could be why similar countries display absolute convergence (see Dowrick and NGuyen (1989) for evidence across OECD countries or Barro and Sala-i-Martin (1991, 1992) for evidence across states of the United States and regions in Europe).

Interesting Result \# 16: The Lucas (1988) growth model predicts conditional convergence in that, in a cross section of countries that differ by initial conditions, the growth rate should be negatively related to initial income only after a measure of human capital is held constant. Thus, the model is consistent with existing empirical evidence.

\section{Savings and Growth}

Other empirical studies suggest that the sign of the convergence coefficient changes once the savings rate is held constant (see Barro (1991) and Mankiw, Romer and Weil (1990)), even without holding proxies for human capital. We want to check whether the Lucas model is consistent with this

29 The question is whether the variable actually used by Barro (1991) "school enrollment" is a good measure of uh. School enrollment in our model is (1-u). To the extent that current school enrollment is correlated with past school enrollment, it is also a measure of the stock of human capital. If most of the variation in uh across countries is due to variation in $h$ rather than $u$, school enrollment will be a good proxy for uh. 
evidence also.

First, let's think about a data set for which all observations approach the same steady state but differ in the "distance" from that steady state the taste and technological parameters $(\alpha, \phi, \theta, \rho$, etc.) are the same for each observation but $z(=k / h)$ varies. To do so, it helps to know something about the policy functions $a(z)$ and $u(z)$. We know from previous analysis that these are downward sloping. Thus, when $z$ ls high, both work effort, $u$, and consumption-capital ratio, a, are low. However, $u$ and a have opposite effects on savings. These offsetting effects can be seen analytically by substituting the expression for output growth (36) into a linear approximation for $a(y / k)$ and solving for the savings rate: ${ }^{30}$

(37) $s=1-E-D \cdot \frac{G_{2}}{\gamma_{y}-G_{1}}$

where $G_{1}$ and $G_{2}$ are defined as above. We have argued that $G_{2}>0$. Therefore $s$ is a positive function of output growth if and only if $D>0$. To examine D, look at the value suggested in (33). For parameters consistent with micro studies, $D$ is positive; savings rates are positively related to growth in the transition.

Second, let's think about economles with different intertemporal elasticities $(i \equiv 1 / \theta)$. Some countries can be near the steady state, others may be at various distances from it. These economies will have different steady state growth rates, savings rates, and output-capital ratios. Since it can be shown that savings rates are decreasing in $\theta$, we write the

Of course, the savings rate is constant when $D=0$ (which is true when (32) holds). 
intertemporal elasticity of substitution as an increasing function of the savings rate:

$$
I(s)=1 / \theta(s) \quad I^{\prime}(s)>0
$$

We can therefore express the growth rate as a function of $s,(u \cdot h)$ and $y$ :

$$
\gamma_{y}=1(s) \cdot\left[-\left(p+\delta_{k}\right)+\alpha \cdot A^{1 / \alpha} \cdot\left(\frac{u \cdot h}{y}\right)^{\frac{1-\alpha}{\alpha}}\right]
$$

For growth rates that are (on average) positive, the Lucas model predicts that output growth depends positively on $s$ and $(u \cdot h)$ and negatively on $y$. Mankiw, Romer and Well (1990) run thls type of regression and find a positive coefficient on savings and human capital and a negative coefficient on Initial income. Hence, the Lucas model of endogenous growth is consistent with their findings.

What if all economies are in the steady state and, in addltion to different intertemporal elasticities, have different human capital productivities ( $\phi)$ ? It can be seen from the expression for steady state growth that the simple correlation between savings and growth will be positive:

(40) $\quad \gamma_{y}^{*}=i\left(s^{*}\right) \cdot(\phi-\rho)$

However, is it true - if all economies are in the steady state - that, holding constant savings rates, $(\mathrm{u} \cdot \mathrm{h})$ matters positively and $y$ matters negatively? Yes, to the extent that $(u \cdot h)$ and $y$ are proxying for $\phi . \phi$ can 
be written as a function of (steady state) $(u \cdot h)$ and $y$ :

$$
\phi=\alpha \cdot\left(\frac{u \cdot h}{y}\right)^{\frac{1-\alpha}{\alpha}}-\delta_{k}
$$

When (41) is substituted into the expression for steady state growth, we get a steady state version of (39).

Interesting Result \#77: The Lucas (1988) model is consistent with the cross-section emplrical finding that growth is negatlvely related to initial income and positively related to savings rates and measures of human capital. Thus, the existing cross-sectlonal emplrical evidence does not distinguish between the transition of the Lucas model and the transition of the standard neoclassical model.

In Mulligan and Sala-1-Martln (1992) we show that the general two-sector models have similar emplrical predictions. Since these cross country tests do not allow us to dlstingulsh between the neoclassical one-sector model and the two-sector endogenous models we also develop further empirical tests.

Interest Rates, Capltal Mobllity and Growth.

Growth theory's predictions for the relationships between growth, interest rates and income have been of questionable empirical relevance. Flrst, as Lucas (1988) and others have noted, capital should flow to poor countries because thelr interest rates should be much higher. This is not an empirical regularity. Second, interest rates should be declining over time. King and Rebelo (1989) argue that this is not true in the U.S., at least as is required by their parameterization of the neoclassical model. Barro (1990b) notes that interest rates have declined since the Civil War.

Before addressing these issues in the Lucas model, we first derive an 
expression for interest rates $\left(r \equiv \partial y / \partial k-\delta_{k}\right)$ :

$$
r=\alpha \cdot(y / k)-\delta_{k}
$$

Using the approximate expression for growth (37), growth can be written as a function of the interest rate: ${ }^{31}$

$$
\gamma_{y}=(r-\rho) / \theta
$$

Therefore, for economies in transition, we should see a trend in interest rates and growth (both should show a trend in the same direction). As argued above, such trends may be consistent with U.S. data. We also predict that growth and interest rates are positively correlated. However, because we cannot say anything a priori about the relationship between income and growth, income and interest rates are not necessarily related. Capital should not necessarily flow to poor countries, capital should flow to high growth countries.

Interesting Result \#17: The two-sector endogenous growth models proposed in this paper predict that high growth countries tend to have larger marginal products of capital and real interest rates. On the other hand, it has no prediction on the relation between the level of income and interest rates. Thus, (unlike the neoclassical model) this model predicts that if we open up international capital markets, we should observe capital flowing from low growth to high growth regions and NOT from rich to poor regions.

31 As discussed above, our approximate output growth expression is exactly equal to consumption growth because $D$ and $E$ were chosen as in (33). 


\section{(IX) CONCLUSIONS.}

In this paper we studied the transitional dynamics of two-sector models of endogenous growth. We found that the necessary condition for endogenous growth allowed us to express the model in terms of one state variable only (Interesting Result \#6). Thus, endogenous growth models are simpler to study than neoclassical models. This alone is a good reason for using them.

We found that if the point-in-time production possibility frontier across the two sectors is linear, the transition takes no real time (Interesting Result \#10). If, on the other hand, the point-in-time production possibility set across the two sectors is strictly convex (strictly concave PPF), there is transition in real time (Interesting Result \#11). In this latter case, the models are ALWAYS globally saddle path stable (Interesting Result \#12).

The transition involves two effects: A substitution or real wage effect that lead people to reduce work effort when physical capital is relatively low (low wages); and a wealth or consumption smoothing effect that lead people to high consumption relative to physical capital, when physical capital is low. We find that the wealth effect dominates: when physical capital is relatively low, agents invest in physical capital through large effort in the final output sector and NOT through high savings. In other words, the two policy functions $u(z)$ and $a(z)$, are downward sloping (Interesting Result \#12). The only exception to this finding is the particular case of Lucas (1988) and only when the elasticity of intertemporal substitution is implausibly large $(\theta<\alpha)$ (Interesting Result \#9).

Finally, we found a bunch of interesting empirical implications. The 
most important is the finding that the two-sector models predict conditional convergence in that in a cross section of economies, the growth rates should be negatively related to initial income, but only after some measure of human capital and/or savings is held constant (Interesting Results \#16 and \#17). Thus, the models are consistent with the existing empirical evidence for a variety of data sets.

We would like to conclude with an important question: how long does it take for our two-sector economies to reach the steady state? ${ }^{32}$. We can gain some intuition about the speed of convergence in the Lucas model by considering the case when $\theta=\alpha$. Since, as we showed in the analysis above, $u(t)$ is constant along the transition, the human capital accumulation constraint says that $\dot{h} / h=x$ for all $t$ so $h(t)=h(0) e^{x t}$. By substituting this expression into the production function of final output we get

$$
\dot{k}(t)=B k(t)^{\alpha}\left(e^{x t}\right)^{1-\alpha}-c(t)-\delta k(t)
$$

which is exactly the accumulation constraint of the one-sector neoclassical growth model. The speed of convergence will therefore be close to that of the neoclassical model: with a physical capital share close to .4 (as it is under a narrow view of physical capital in the absence of externalities) the speed of convergence is fast (half lives of 5.5 to 11 years) ${ }^{33}$. If we think of capital in a broad sense and/or if there are capital externalities, the capital share will be larger. For instance, if the physical (or non-human)

32 Note that we are not asking whether transitions are important. We believe that if transitions are long, they are certainly important. Yet they may be (empirically) important even when they are not very long. 
capital share $\alpha$ is about .8, then the speed of convergence is close to $2 \%$ per year with a half life of 35 years.

As we allow $\theta$ to depart from $\alpha$ (say $\theta>\alpha$ ), there are two effects that could modify this conclusion. First, $u(z)$ becomes downward sloping, which tends to accelerate convergence as people work harder in the final output sector when physical capital is scarce. But, second, a(z) also becomes downward sloping which tends to decelerate convergence as people save relatively less when physical capital is low. Qualitatively, we cannot evaluate the net effect. Yet it seems plausible that if $u(z)$ is "fairly" flat, than the consumption effect may dominate; convergence would be slower than in a similarly parameterized one-sector model. ${ }^{34}$ We have argued that large adjustment costs lead to flat policy functions for work effort. Therefore, convergence speeds can be slower than in a comparable one-sector model if adjustment costs are large enough.

By log-linearizing the dynamic solution around the steady state, we can estimate the local speed of convergence. The state-like variable follows the following process:

$$
\ln z(t)-\ln z^{*}=e^{-\lambda t}\left(\ln z(0)-\ln z^{*}\right)
$$

where $\lambda$ is the speed of convergence. Note that $z$ to any power will have the same speed of convergence as $z$. Therefore the potential-output-to-capital ratio (in either our model or a comparable one-sector model) also has a speed of convergence $\lambda$, So does output in a comparable one-sector model.

34 By similarly parameterized, we mean that the capital shares, intertemporal elasticities, capital depreciation rates, and steady state growth rates are the same. 
In our model, output grows without bounds, so (usually) we can not think about convergence of output in the same way.

For the benchmark parameters of Table 1 (capital share of .5), we find the (local) speed of convergence to be $10 \%$ per year. This corresponds to a half-life of about 7 years. If the social physical capital share is .8 the speed of convergence is $\lambda=.025$ with a half-life of 28 years. The introduction of decreasing point-in-time technologies (reflecting the difficulty to transform human capital from one sector to the other at a point in time) reduces the speed of convergence even further. For instance if we let $\psi_{1}$ be .7 rather than 1 (and if we adjust the productivity parameter $\phi$ so as to keep the steady state growth rate constant) the speed of convergence is .0149 with a half life of 47 years.

We do not need to assume such large physical capital shares to get long transitions. For instance, with $\alpha=.6$ and $\psi_{1}=.5$ (and, again, adjusting the productivity $\phi$ so as to get similar steady state growth rates) we get a $\lambda$ equal to .028 and a half iife of 25 years.

Similar results are true for the more general model. We already know that, if the production functions in both sectors are identical and if there are no adjustment costs, the speed of convergence is infinity. If the physical capital share in the final output sector is set to .6 $(\alpha=.6)$ and the share in the human capital sector is .2 $(\beta=2)$, with decreasing point-in-time returns in all sectors $\left(\varepsilon_{1}=.2, \varepsilon_{2}=.3, \psi_{1}=.1, \psi_{2}=.4\right)$, the speed of convergence is .036 with a half life of about 20 years. Of course, the larger the adjustment costs, the longer the transitions. Thus, for very plausible parameterizations, the two-sector economies under our consideration take a long time to reach the neighborhood of the steady state. 


\section{REFERENCES}

Abel, A. and O. Blanchard, "An intertemporal equilibrium model of savings and investment", Econometrica 51, 3, May 1983.

Barro, R., J., "Are Government Bonds Net Wealth?", Journal of Political Economy, 1974.

Barro, R., J., "Government spending in a simple madel of endogenous growth", Journal of Political Economy, October 1990a.

Barro, R., J.,"Economic growth in a cross section of countries", Q.J.E., May (1991)

Barro, R., J. and X. Sala-i-Martin, "Convergence across states and regions", Brookings Papers of Economic Activity, 1991:I. (1991)

Barro, R., J. and X. Sala-i-Martin, "Convergence", forthcoming J.P.E. (1992)

Barro, R., J. and X. Sala-i-Martin, "Economic growth" unpublished manuscript, Chapter One (1991b).

Bernard, A. and S. Durlauf, "Convergence of international output movements", mimeo Stanford University, 1991.

Burmeister, E. "Capital theory and dynamics", Cambridge U. Press, 1980.

Caballe, J, and M. Santos, "On Endogenous Growth with Physical Capital", mimeo Universitat Autonoma de Barcelona, 1991.

Cass, D., "Optimum growth in an aggregative model of capital accumulation", Review of Economic Studies, July 1965.

Chamley, C. "Externalities and Dynamies in Models of Learning or Doing", Institute for Economic Development Discussion Paper Series, \#17, Boston University, (1991) 
Faig, M. "A simple economy with human capital: transitional dynamics, technology shocks, and fiscal policies", mimeo Toronto May 1991.

Heckman, J., "A life-cycle model of earnings, learning, and consumption", J.P.E., 1976.

Jones, L. and R. Manuelli, "A convex model of equilibrium growth", J.P.E, october 1990.

Jorgenson, D., "Capital theory and investment", AER, may 1963.

----, and Jun-Young Yun, "Tax reform and U.S. economic growth", JPE october 1990.

Judd, K. L., "Minimum weighted residual methods for solving dynamic economic models", mimeo Hoover Institution, July 1990

King, R. and S. Rebelo, "Public policy and economic growth: developing neoclassical implications", JPE October 1990.

Koopmans, T. C., "On the concept of optimal growth", in the Econometric Approach to Development Planning", North Holland, Amsterdam, 1965.

Kurz, M., "The general instability of a class of competitive growth processes", Review of Economic Studies, March 1968, p. 155.

Lucas, R. E., "On the mechanics of economic development", J.M.E., 1988.

Lucas, R. E., "Supply-Side Economics: An Analytical Review", Oxford Economic Papers 421990.

Mankiw, G., D. Romer, and D. Weil, "A contribution to the empirics of economic Growth", mimeo Harvard 1990.

Mulligan, C. B., "A note on the time-elimination method for solving recursive dynamic economic models", NBER WP, November 1991.

Mulligan, C. B., and X. Sala-i-Martin, "Endogenous growth models with public investment", mimeo Yale University (1991) 
Mulligan, C. B., and X. Sala-1-Martin, "Two-Sector growth models and the convergence hypothesis", (1992)

Null Hypothesis, "Is grandma a closet Keynesian?", in Fred Flintstone, and Barnie Rubble editors, "Stone age economics: a survey of current developments", Bedrock university press, Bedrock, IA, 1987.

Press, William H., et al. "Numerical Recipes in C: The Art of Sclentlflc Computing". Cambridge: Cambridge University Press, 1990.

Ramsey, F., "A mathematical theory of saving" Economic Journal, 38, December 1928, 543-559.

Rebelo, S., "Long Run Policy Analysis and Long Run Growth", J.P.E., June 1991.

Romer, P., "Increasing Returns and Long Run Growth", J.P.E., 94, p1002-1037, (1986)

Ryder, H. E. Jr., "Optimal Accumulation In a Two-Sector Neoclassical Economy with Non-Shiftable Capltal", Journal of Political Economy, 77, August 1969, p. 665-683.

Sala-i-Martin, X., "Lecture notes on economic growth (I) and (II)", NBER working paper \#3654 and 3655, December 1990.

Srinivasan, T. N., "Optimal savings in a two-sector model of growth", Econometrica, 32, 3, July 1964.

Summers, R. and A. Heston, "A new set of international comparisons of real product and price levels: estimates for 130 countries", Review of Income and Wealth, XXXIV, 1988. 
The first order conditions to the general program with respect to $c, k, h$, $\mathrm{u}$, and $\mathrm{v}$ are respectively:

(A1) $e^{-\rho t-\theta} c^{-\theta}=\lambda$

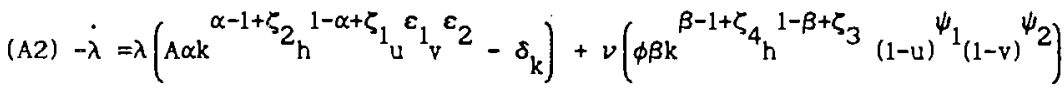

(A3) $\dot{v}=\lambda\left(A^{\alpha+\zeta_{2}}{ }_{(1-\alpha) h}^{-\alpha+\zeta_{1} \varepsilon_{1} \varepsilon_{v}}\right)+v\left(\phi(1-\beta) k^{\beta+\zeta_{4}}{ }^{-\beta+\zeta_{3}}{ }_{(1-u)} \psi_{1(-v)} \psi_{2}-\delta_{h}\right)$

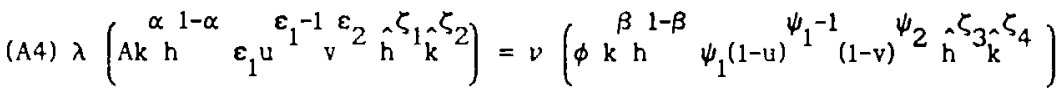

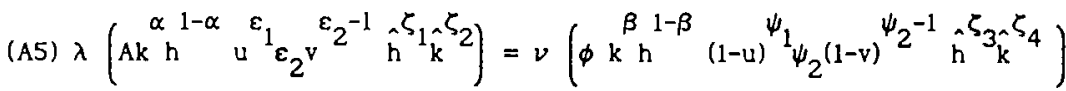

where the aggregate consistency conditions $\hat{h}=h$ and $\hat{k}=k$ have been used ${ }^{35}$. The two limiting transversality conditions are

(A6) $\quad \lim _{t \rightarrow \infty} \lambda(t) k(t)=0$

and

$\lim _{t \rightarrow \infty} v(t) h(t)=0$

We can substitute the ratio of shadow prices in (A4) into equation (A2) to get an expression for the growth rate of the shadow price of physical capital $\lambda / \lambda$. Also, by taking logarithms and derivatives of (A1) we get the growth rate of consumption as a function of $\dot{\lambda} / \lambda$. If we put the two together we get an expression for consumption growth

35 The representative agent has the representative or average amount of both types of capital goods. Hence, it must be the case that $h=h$ and $k=k$. 
(A7) $\gamma_{c}=(1 / \theta)\left(A k^{\alpha-1+\zeta_{2}{ }^{1-\alpha+\zeta_{1}} u^{\varepsilon_{1}-1} v^{\varepsilon_{2}}\left(\alpha \psi_{1} u+\varepsilon_{1} \beta(1-u)\right) / \psi_{1}-\left(\delta_{k}+\rho\right)}\right)$

where $\gamma_{c}$ is defined to be the growth rate of consumption, $\gamma_{c}=c / c$.

To find a relation between the fraction of physical capital used in the final output sector and the fraction of human capital used in the final output sector between the shares of capitals employed in each sector (u and v), divide equation (A4) by equation (A5) and get

(A8) $v(u(t))=\frac{u(t)}{\Delta+u(t)(1-\Delta)} \quad$ for all $t$

where $\Delta \equiv \varepsilon_{1} \psi_{2} /\left(\varepsilon_{2} \psi_{1}\right)$ is a constant. This is equation (8) in the text. Take now logarithms and time derivatives of both sides of equation (A4) and use (A8) to get a relation between the growth rate of the relative shadow price of the two capital goods $\left(\gamma_{\lambda}-\gamma_{\nu}\right)$, the growth rates of the two capital stocks and work effort $\left(\gamma_{k}, \gamma_{h}\right.$, and $\left.\gamma_{u}\right)$ and the level of work effort, $u$. We can also plug the relative shadow price from (A5) into (A3) to get a value for the growth rate of the shadow price of human capital, $\dot{v} / \nu$. Using these last two equations and (A7) we get

(A9) $\gamma_{u}=$

$g / h(1-u)\left(\left[(1-\alpha) u \psi_{1}+\varepsilon_{1}(1-\beta)(1-u)\right] / \varepsilon_{1}\right)-\theta \gamma_{c}+\left(\alpha-\beta+\zeta_{2}-\zeta_{4}\right) \gamma_{k}+\left(\beta-\alpha+\zeta_{1}-\zeta_{3}\right) \gamma_{h}-\left(\rho+\delta_{h}\right)$

where denominator $=(1-u)^{-1}\left(\left(1-\varepsilon_{1}\right)+u\left(\varepsilon_{1}-\psi_{1}\right)-\frac{(1-u) \varepsilon_{2}+u \psi_{2} / \Delta}{1-\left(1-\Delta^{-1}\right) u}\right)$ and $g$ is defined in (3) in the text. Equation (A9) corresponds to (14) in the text. 
TABLE 1: BENCHMARK MODEL \# 1

STEADY STATE ANALYSIS

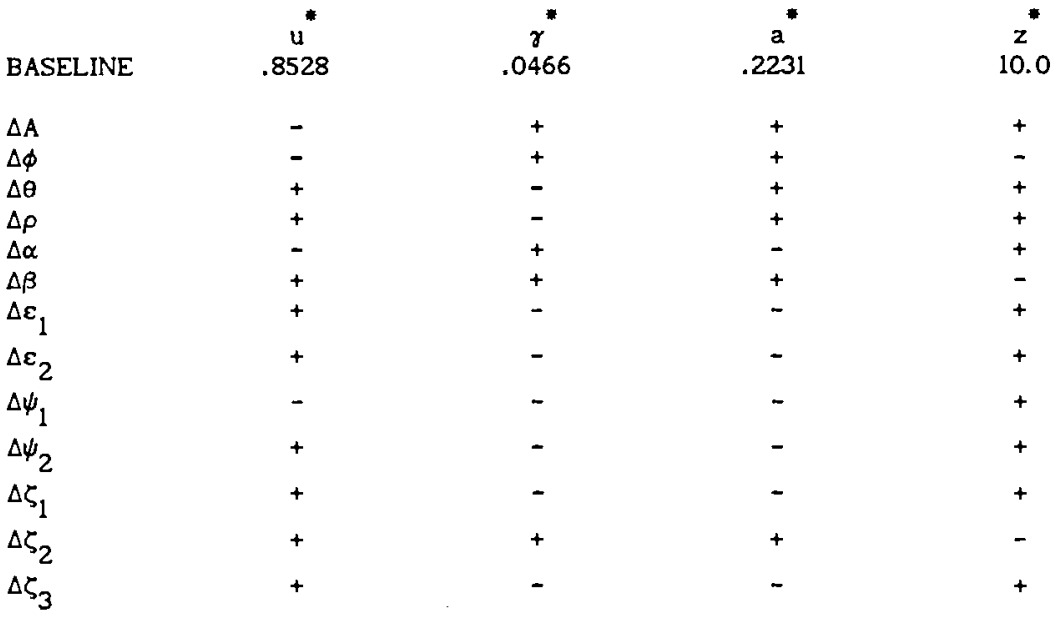

Notes to Table 1: the baseline parameters are: $\varepsilon_{1}=1-\alpha, \varepsilon_{2}=\alpha, \psi_{1}=(1-\beta)$, $\psi_{2}=\beta, \rho=.065, \theta=2, \alpha=.5, \beta=.5, A=1, \phi=1, \zeta_{1}=\zeta_{2}=\zeta_{3}=\zeta_{4}=0, \delta_{k}=0, \delta_{h}=0, n=0$.

TABLE 2: BENCHMARK MODEL \# 2 (LUCAS 1988) STEADY STATE ANALYSIS

$\begin{array}{lcccc} & \text { u } & \boldsymbol{u}^{*} & \mathrm{a}^{*} & \mathrm{z}^{*} \\ \Delta \mathrm{A} & .8250 & .0175 & .1825 & 20.625 \\ \Delta \phi & 0 & 0 & + & + \\ \Delta \theta & - & + & + & + \\ \Delta \rho & + & - & + & + \\ \Delta \alpha & + & 0 & + & + \\ \Delta \zeta_{1} & 0 & + & + & - \\ \Delta \zeta_{2} & + & + & + & +\end{array}$

Notes to Table 2: the baseline parameters are: $\varepsilon_{1}=1-\alpha, \varepsilon_{2}=0, \psi_{1}=1, \psi_{2}=0$, $\rho=.065, \theta=2, \alpha=.5, \beta=0, A=1, \phi=.1, \zeta_{1}=\zeta_{2}=\zeta_{3}=\zeta_{4}=\delta_{k}=\delta_{h}=n=0$ 
Figure 1: Point-in-Time Technologies
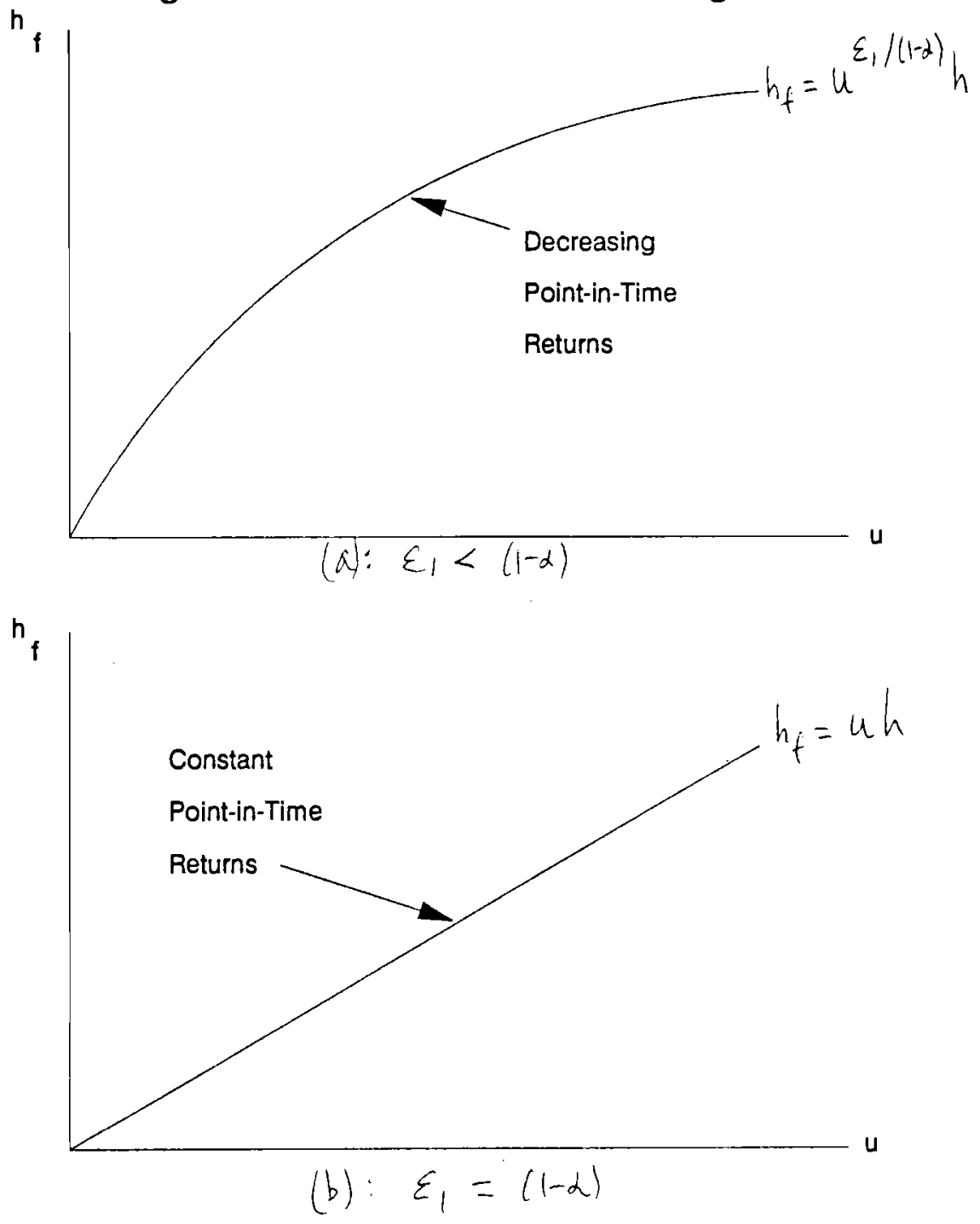


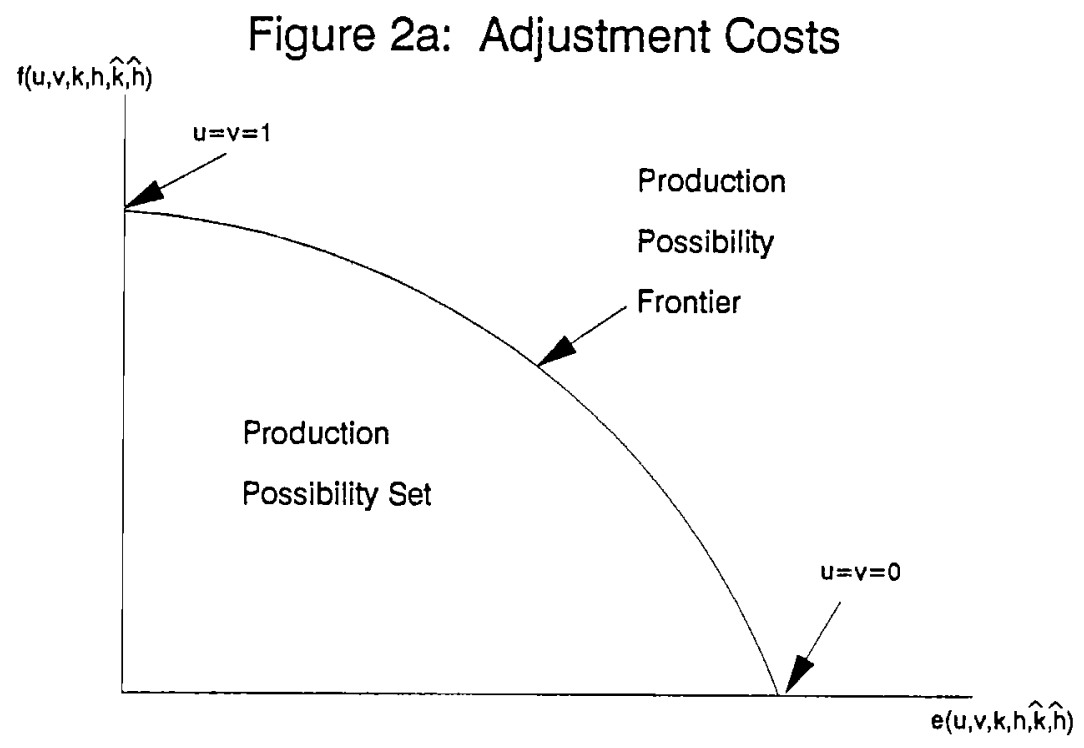

Figure 2b: No Adjustment Costs

$f(u, v, k, h, \hat{k}, \hat{h})$

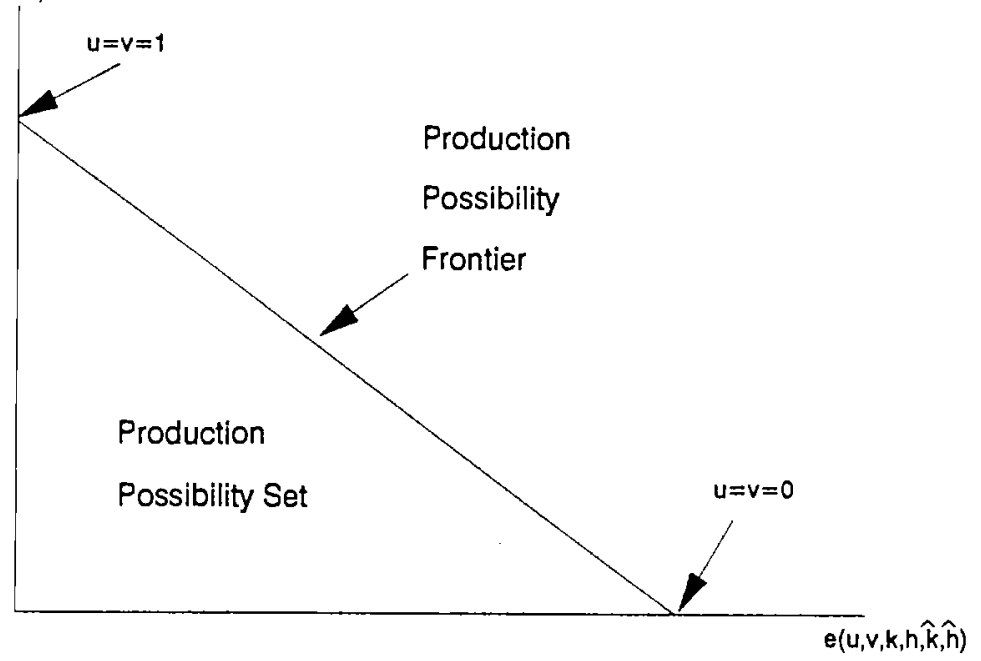


Figure 3: Optimal Static Sectoral Allocation

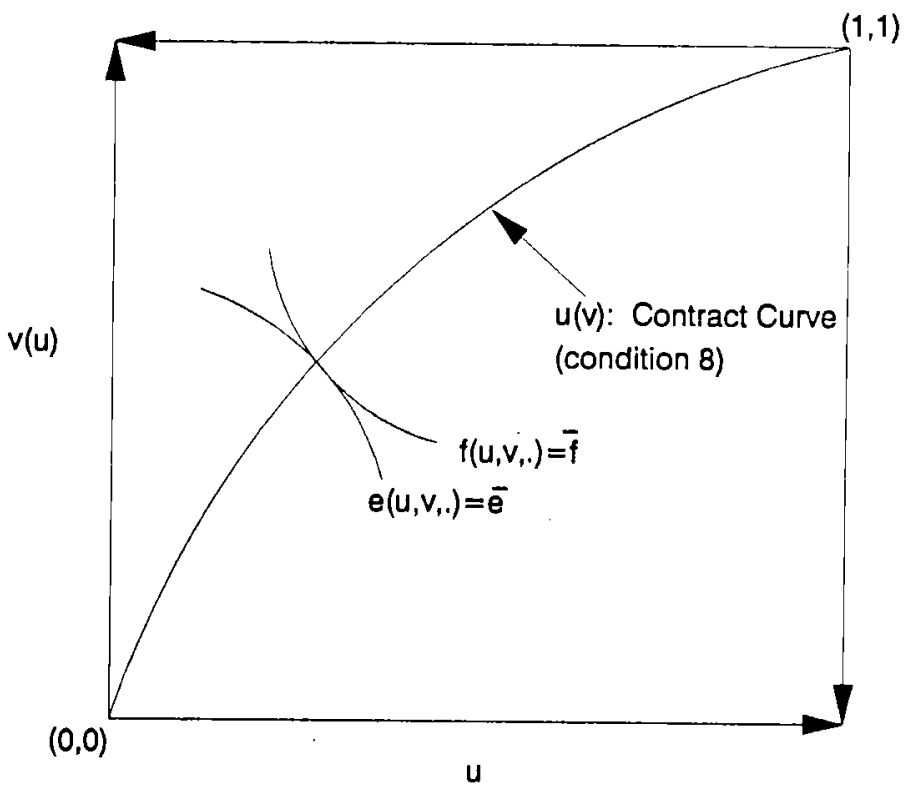


Fig 5(a). $u(z)$ in the Lucas model. theta >alpha.

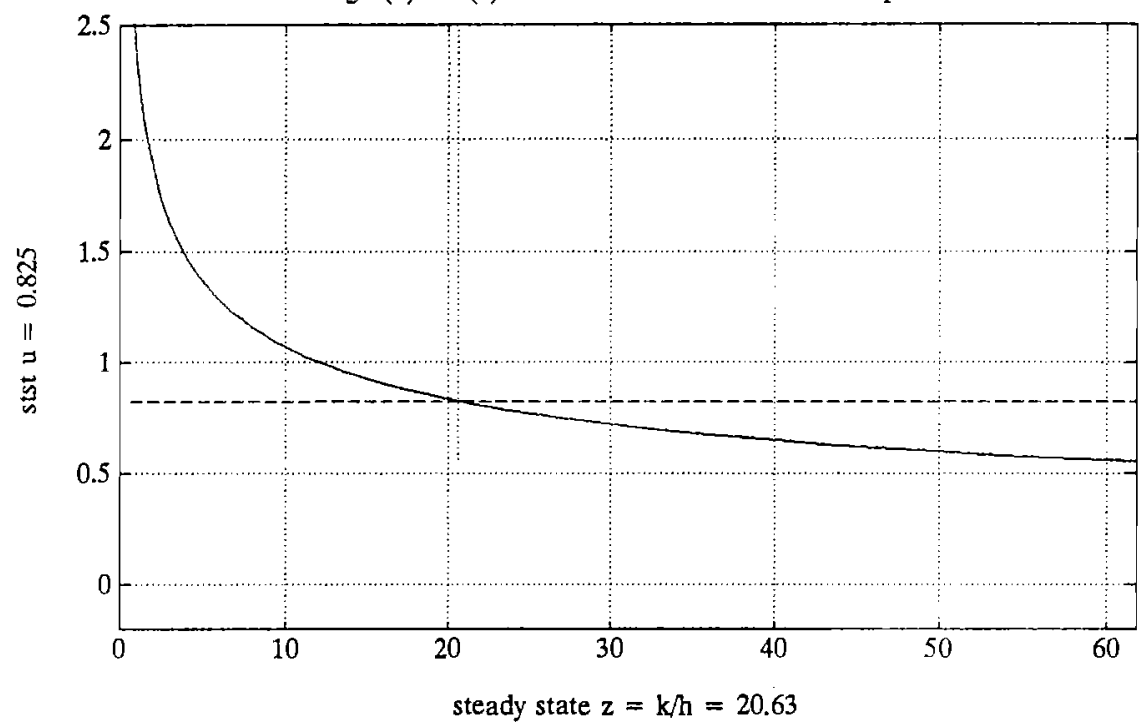

Fig 5(a). $a(z)$ in the Lucas model. theta >alpha.

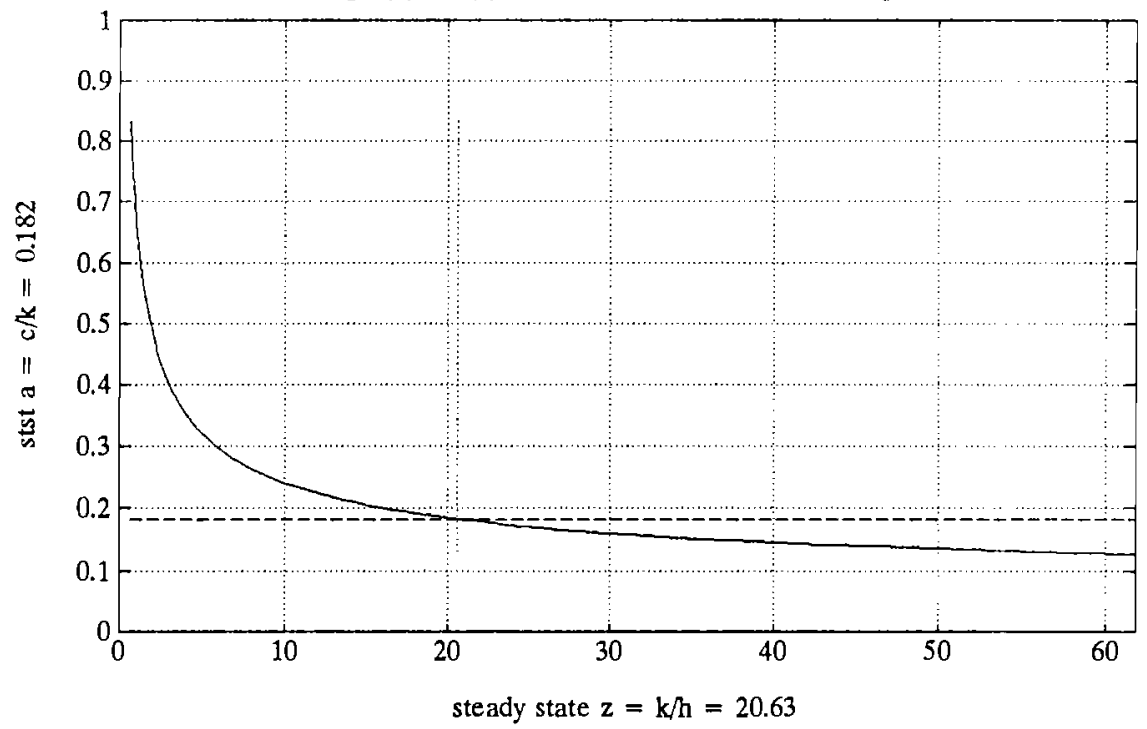


Fig 5(b). $u(z)$ in the Lucas model. theta<alpha.

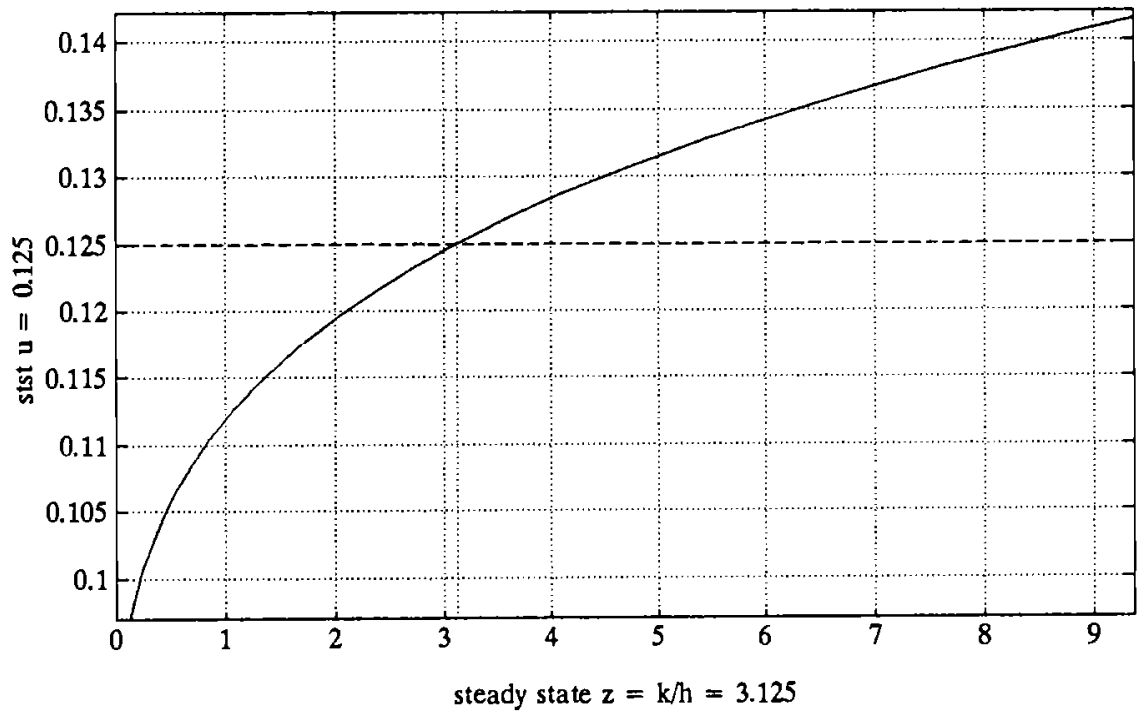

Fig 5(b). a(z) in the Lucas Model. theta<alpha.

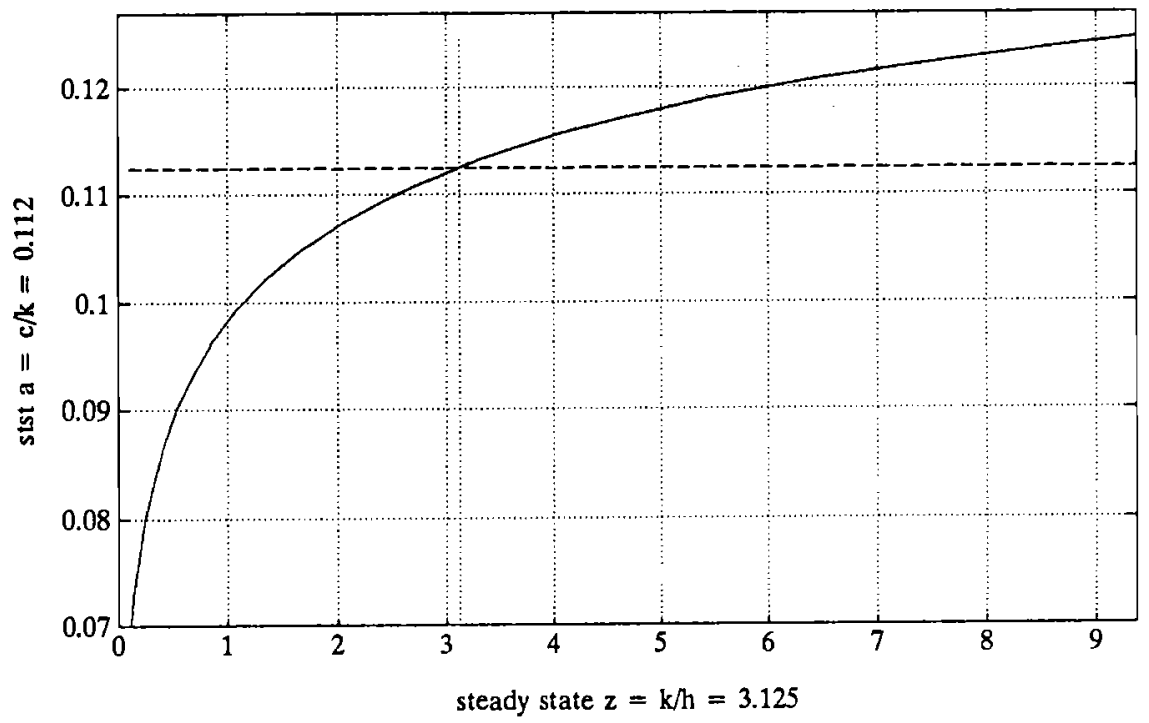


Fig 5(c). $u(z)$ in the Lucas model. theta=alpha.

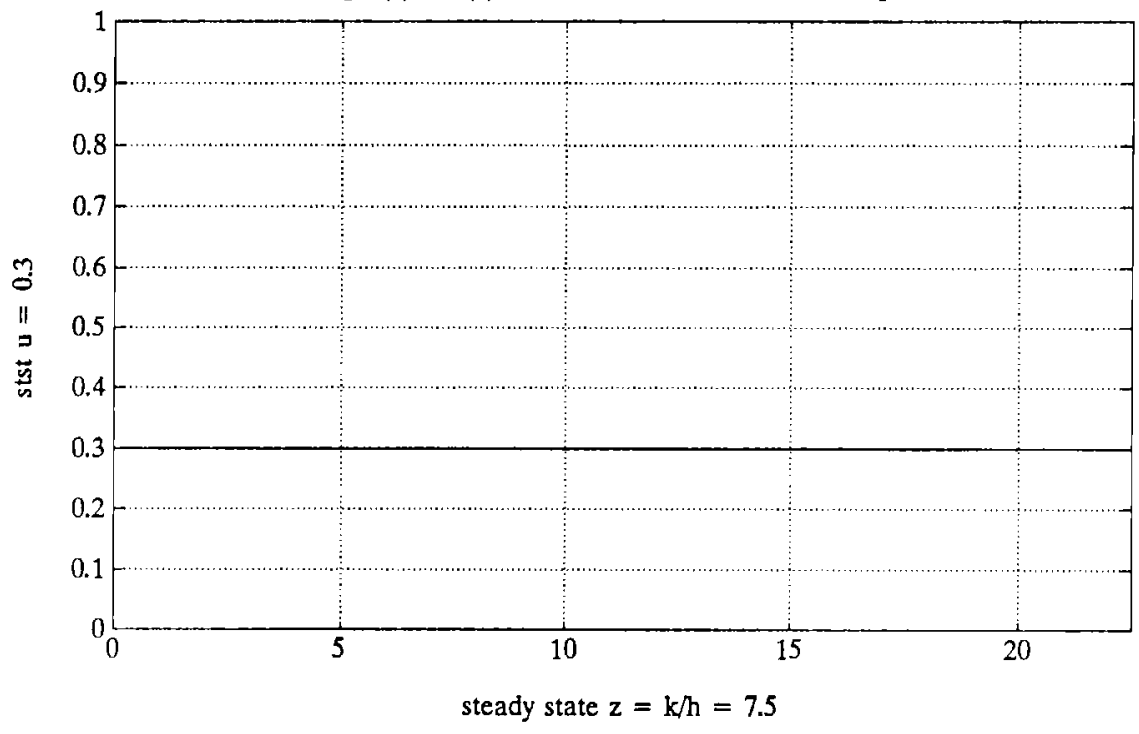

Fig 5(c). a(z) in the Lucas model. the ta=alpha.

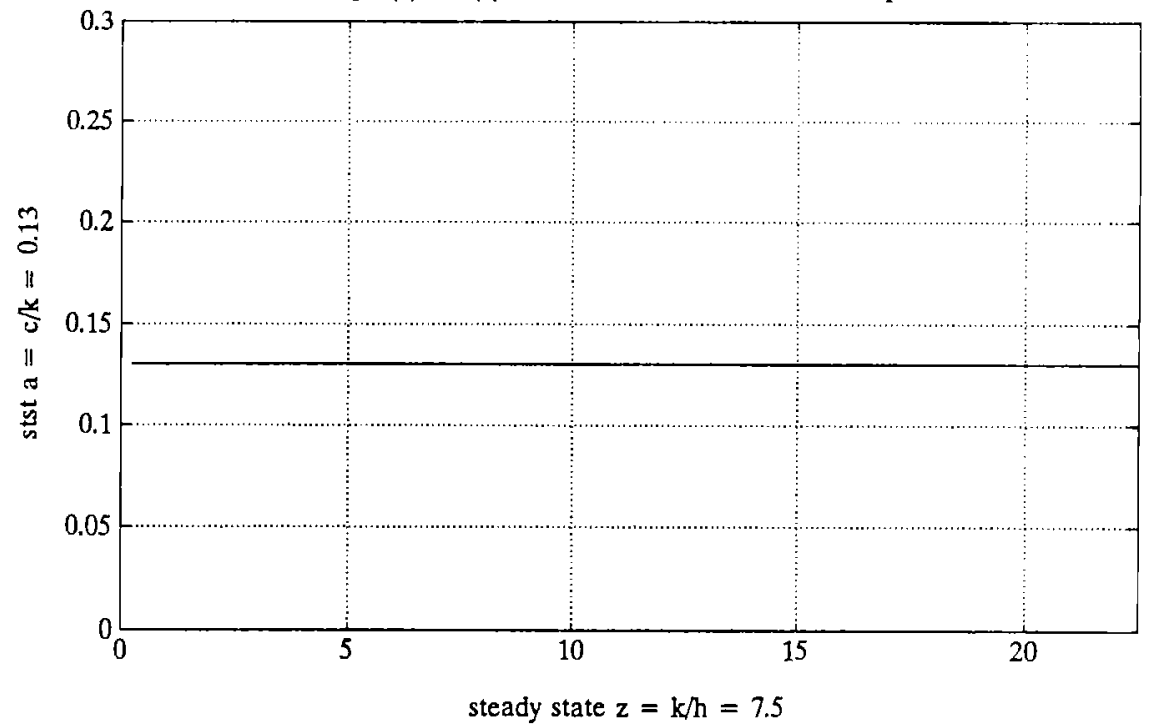


Fig 6. $u(z)$ in the absence of adjustment costs.

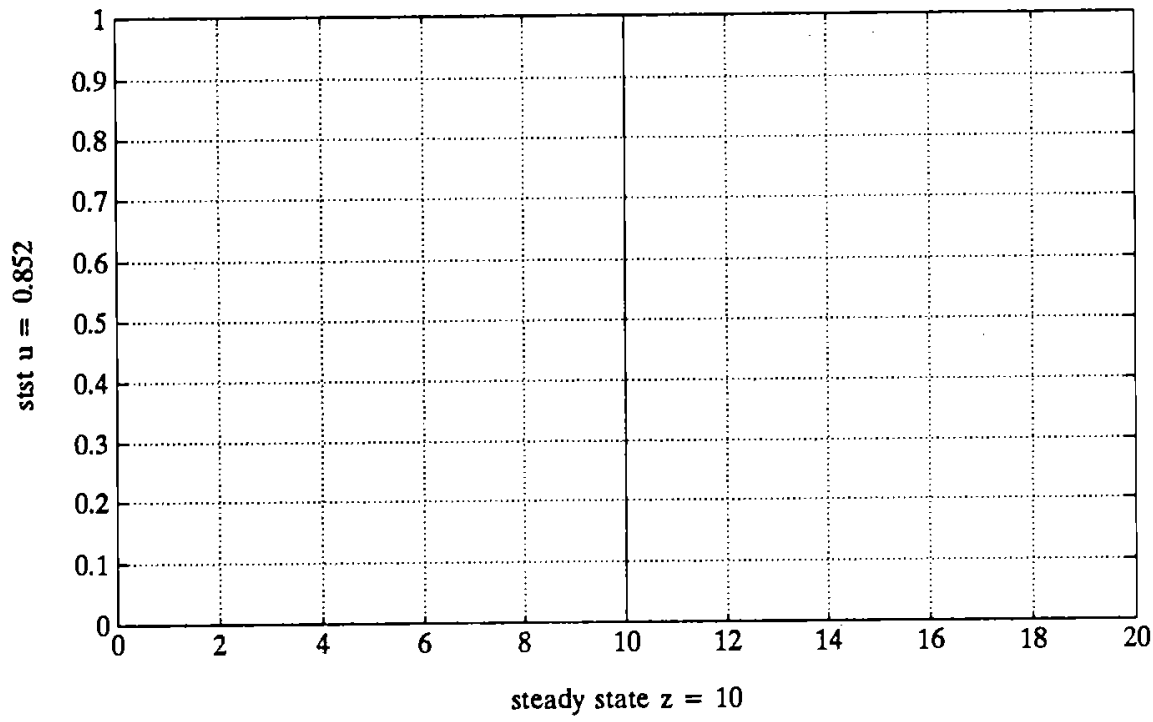

Fig 6. $a(z)$ in the absence of adjustment costs.

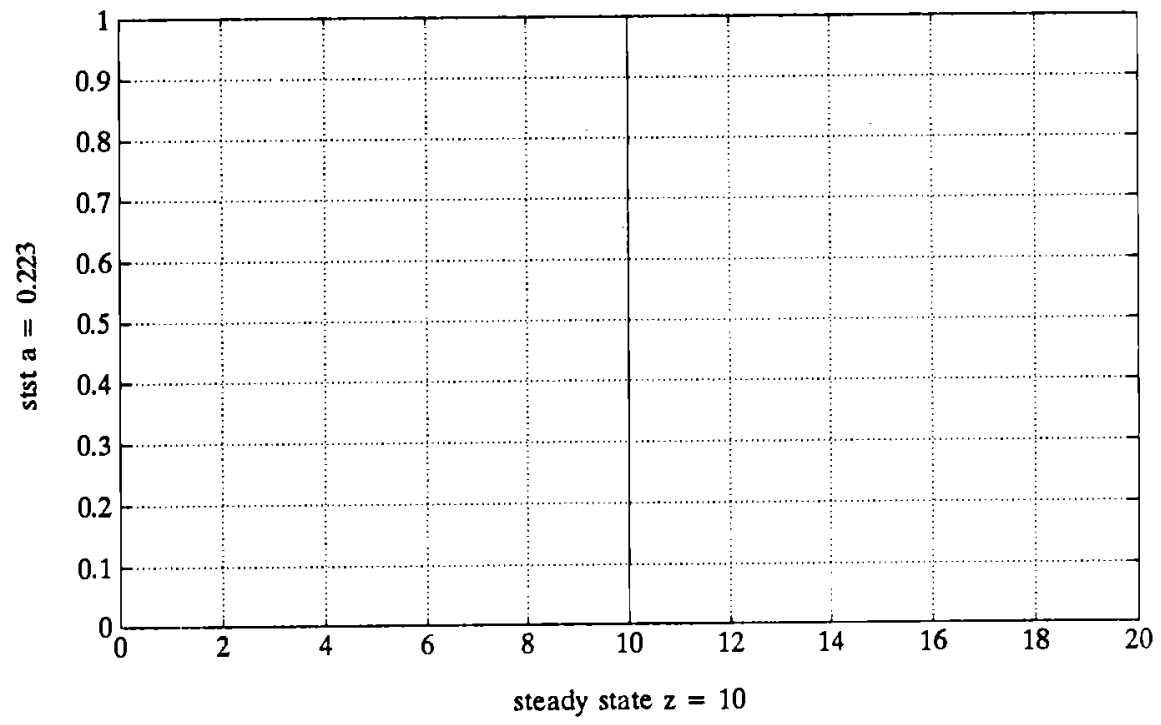


Fig 7. $u(z)$ when production functions are different. alpha $=.6$, beta $=.4$.

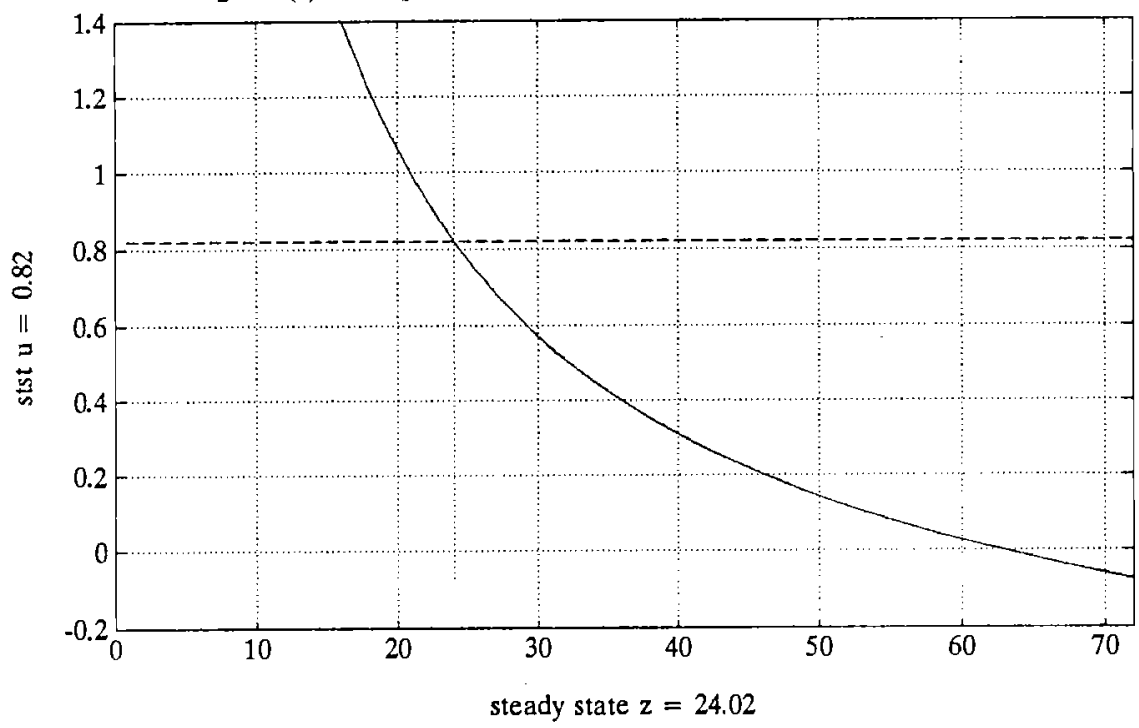

Fig 7. $\mathrm{a}(\mathrm{z})$ when production functions are different. alpha $=.6$, beta $=.4$.

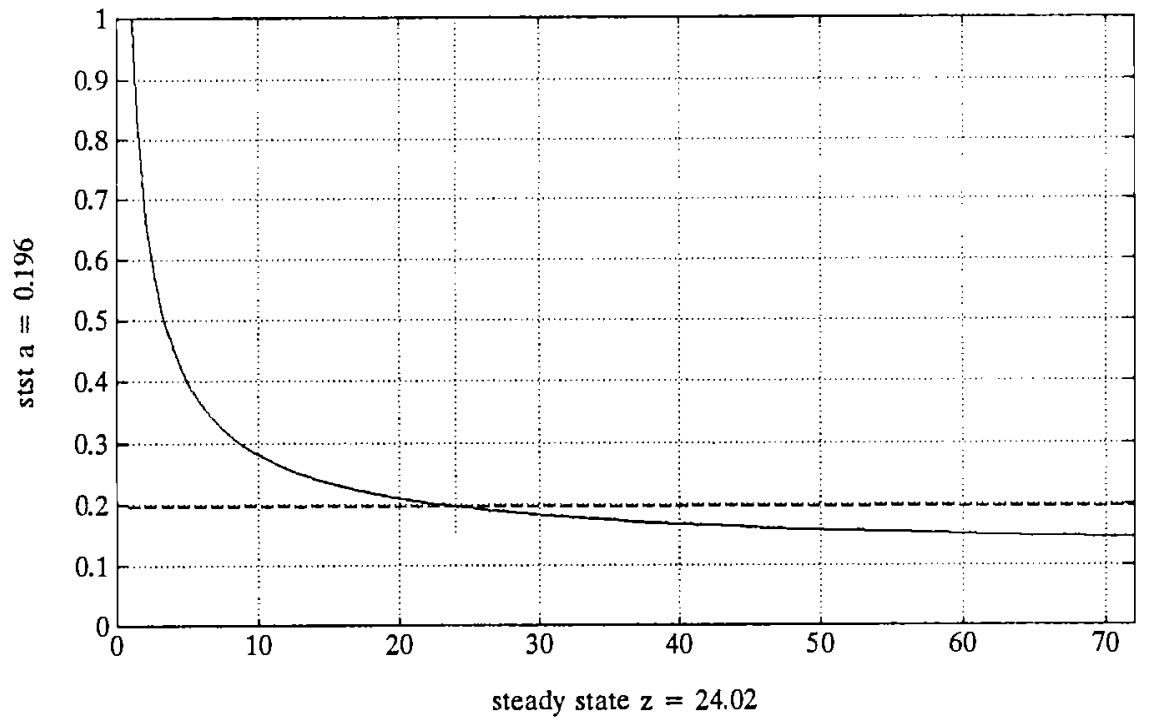


Fig $8(a)$. u(z) when decreasing point-in-time returns in final output sector.

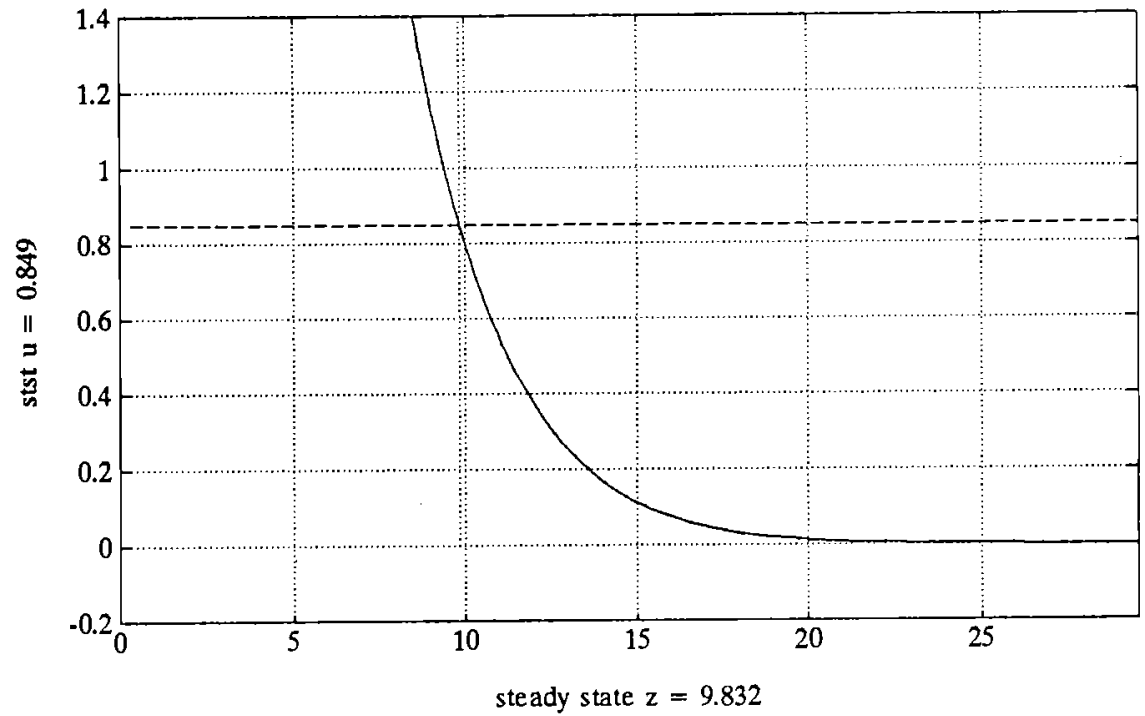

Fig $8(a) . a(z)$ when decreasing point-in-time returns in final output sector.

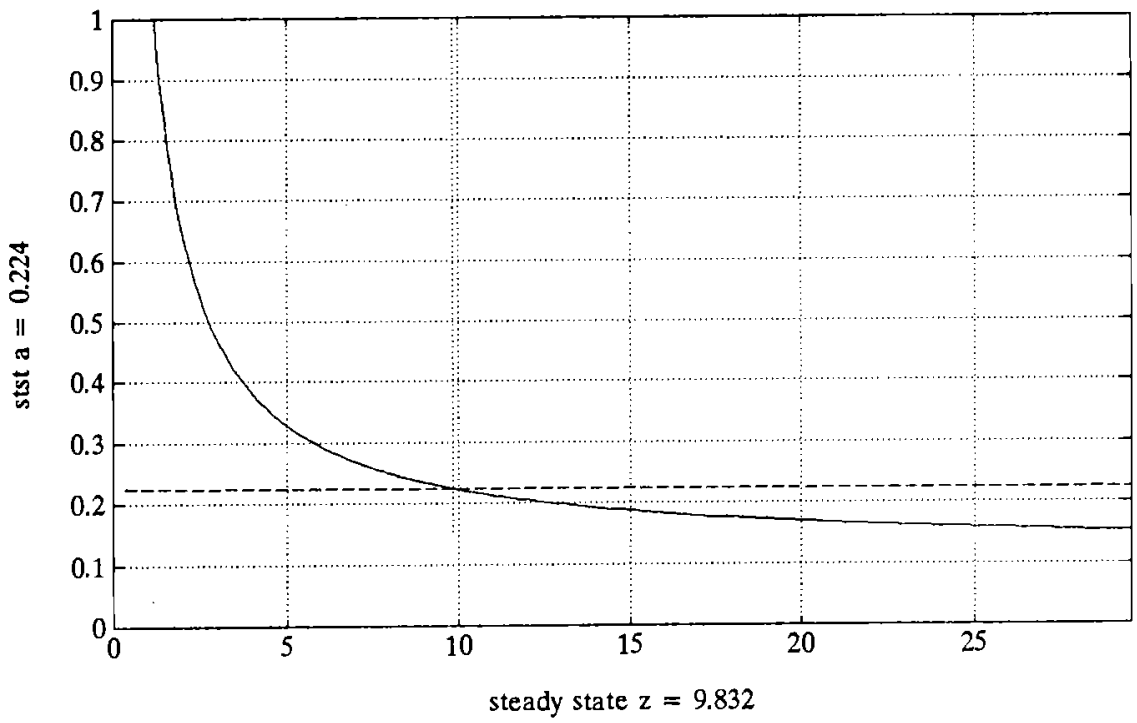


Fig $8(b) . u(z)$ when decreasing point-in-time returns in human capital sector.

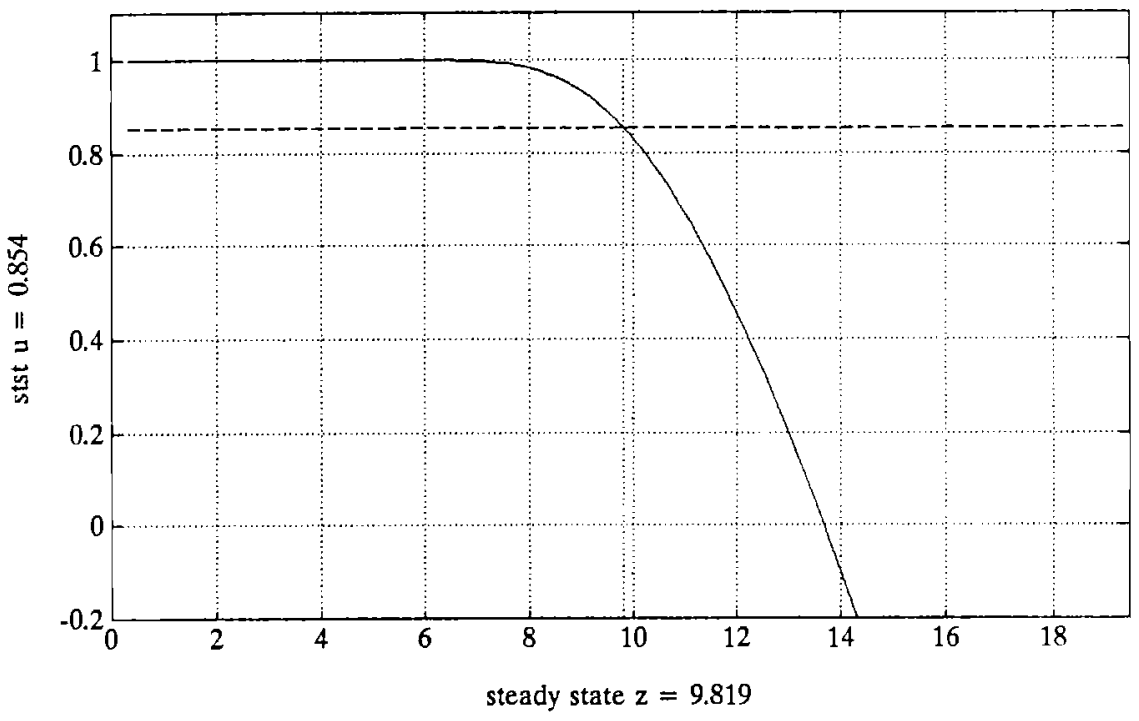

Fig 8(b). a(z) when decreasing point-in-time returns in human capital sector.

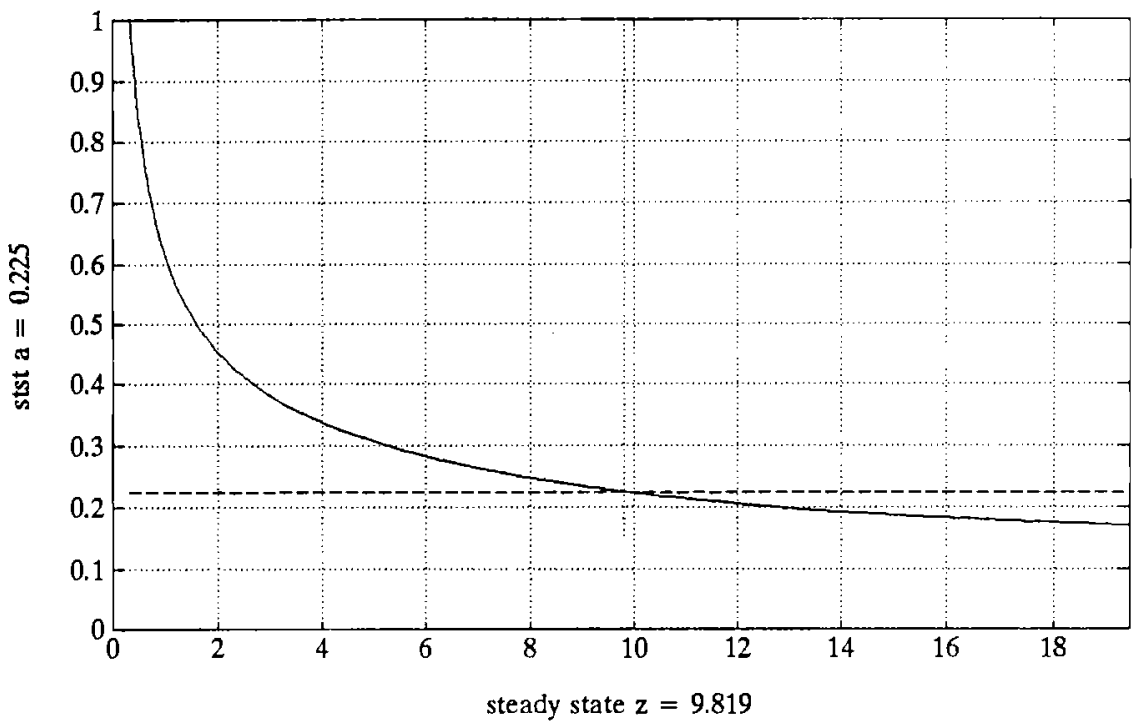


Fig $8(c)$. $u(z)$ when decreasing point-in-time returns in both sectors.

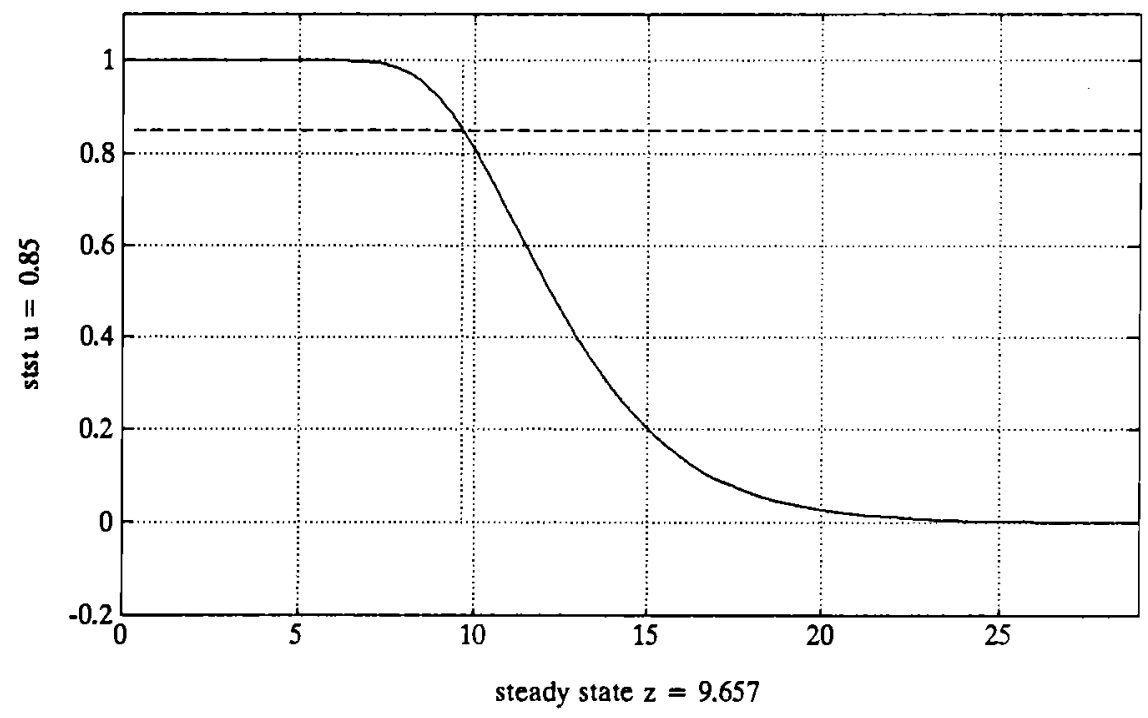

Fig $8(c) . a(z)$ when decreasing point-in-time returns in both sectors.

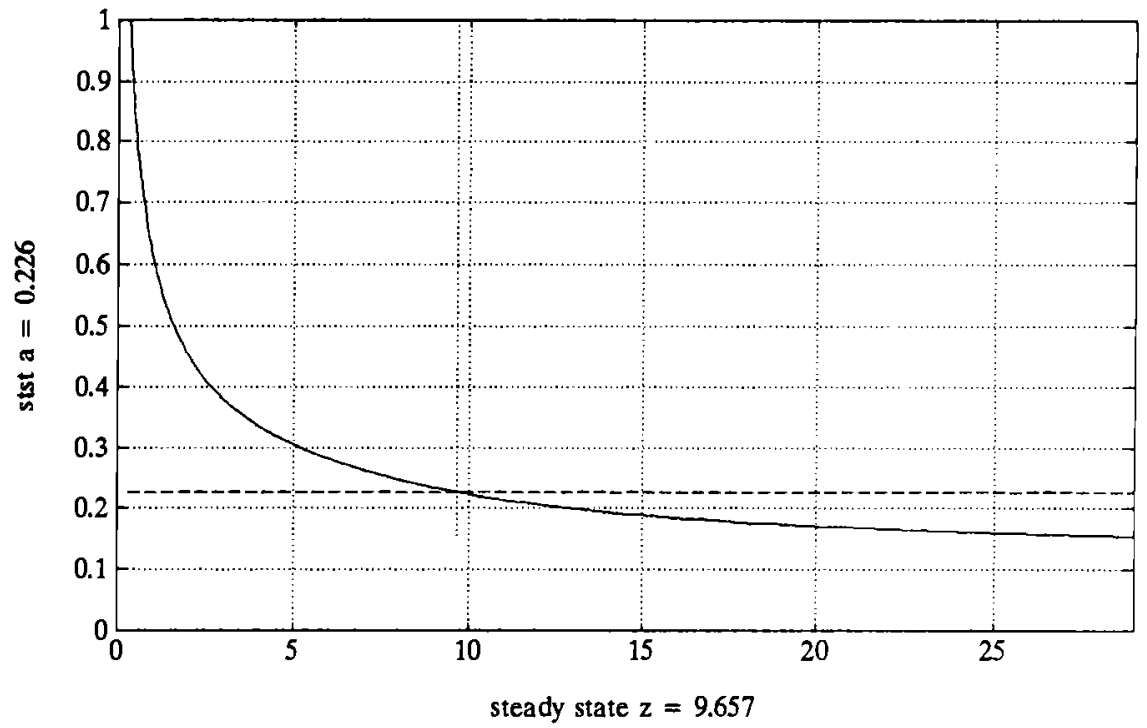

